\title{
AN AERIAL RADIOLOGICAL SURVEY OF THE PILGRIM STATION NUCLEAR POWER PLANT AND SURROUNDING AREA
}

PLYMOUTH, MASSACHUSETTS

DATE OF SURVEY: OCTOBER 19-23, 1995 


\section{DISCLAIMER}

This report was prepared as an account of work sponsored by an agency of the United States government. Neither the United States government nor an agency thereof, or any of their employees, makes a warranty, express or implied, or assumes legal liability or responsibility for the accuracy, completeness, or usefulness of any disclosed information, apparatus, product, or process, or represents that its use would not infringe privately owned rights. Reference herein to a specific commercial product, process, or service by trade name, trademark, manufacturer, or otherwise does not necessarily constitute or imply an endorsement, recommendation, or favoring by the United States government or an agency thereof. The views and opinions of the authors expressed herein do not necessarily state or reflect those of the United States government or an agency thereof.

This report has been reproduced directly from the best available copy.

This report is available to DOE and DOE contractors from the Office of Scientific and Technical Information, P.O. Box 62, Oak Ridge, TN 37831. Call (423) 576-8401 to obtain prices.

This report is available to the public from the National Technical Information Service, U.S. Department of Commerce, 5285 Port Royal, Springfield, VA 22161. Call (703) 487-4650 for information. 


\section{DISCLAIMER}

Portions of this document may be illegible in electronic image products. Images are produced from the best available original document. 


\title{
AN AERIAL RADIOLOGICAL SURVEY OF THE PILGRIM STATION NUCLEAR POWER PLANT AND SURROUNDING AREA
}

\author{
PLYMOUTH, MASSACHUSETTS
}

DATE OF SURVEY: OCTOBER 19-23, 1995

\author{
A. E. Proctor \\ Project Scientist
}

\section{REVIEWED BY}

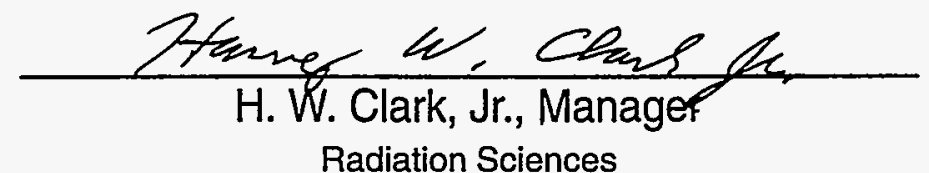

Radiation Sciences

This Document is UNCLASSIFIED

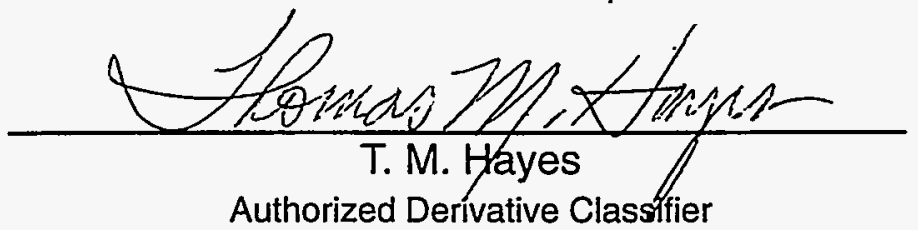

This work was performed for the U.S. Nuclear Regulatory Commission by EG\&G Energy Measurements, Inc., and Bechtel Nevada through an Economy Act Order transfer of funds to Contract Number DE-AC08-93NV11265 (EG\&G/EM) and Contract Number DE-AC08-96NV11718 (Bechtel Nevada) with the U.S. Department of Energy. 


\begin{abstract}
Terrestrial radioactivity surrounding the Pilgrim Station Nuclear Power Plant was measured using aerial radiological survey techniques. The purpose of this survey was to document exposure rates near the plant and to identify unexpected, man-made radiation sources within the survey area. The surveyed area included land areas within a three-mile radius of the plant site. Data were acquired using an airborne detection system that employs sodium iodide, thallium-activated detectors. Exposure rate and photopeak counts were computed from these data and plotted on aerial photographs of the survey area. Several ground-based exposure measurements were made for comparison with the aerial survey results. Exposure rates in areas surrounding the plant site varied from 6 to 10 microroentgens per hour, with exposure rates below 6 microroentgens per hour occurring over bogs and marshy areas. Man-made radiation was found to be higher than background levels at the plant site. Radiation due to nitrogen-16, which is produced in the steam cycle of a boiling-water reactor, was the primary source of activity found at the plant site. Cesium-137 activity at levels slightly above those expected from natural fallout was found at isolated locations inland from the plant șite. No other detectable sources of man-made radioactivity were found.
\end{abstract}




\section{CONTENTS}

Abstract

\section{Sections}

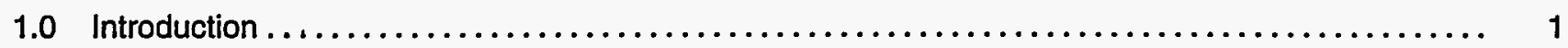

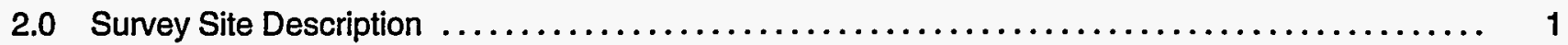

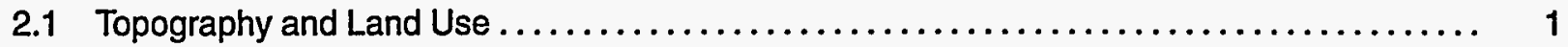

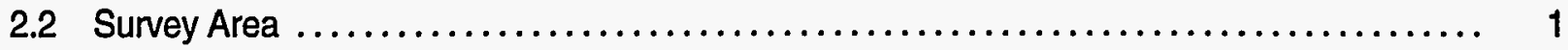

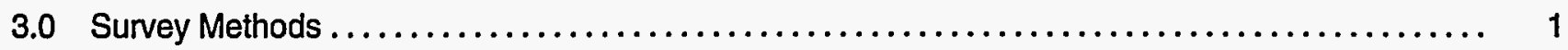

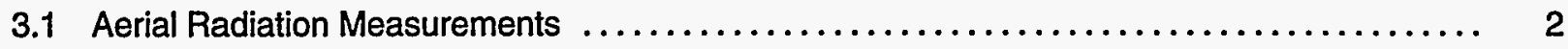

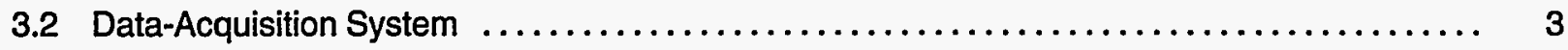

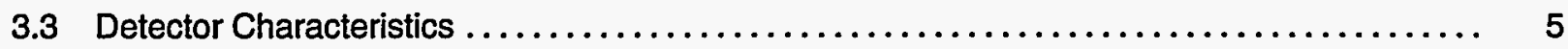

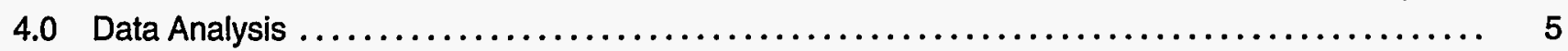

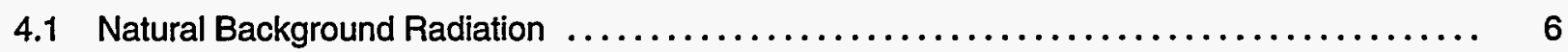

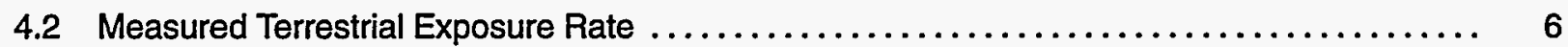

4.3 Identifying Sources of Man-Made Radiation from Aerial Survey Data $\ldots \ldots \ldots \ldots \ldots \ldots \ldots$

4.4 Isotope-Specific Information from Aerial Survey Data $\ldots \ldots \ldots \ldots \ldots \ldots \ldots \ldots \ldots \ldots \ldots$

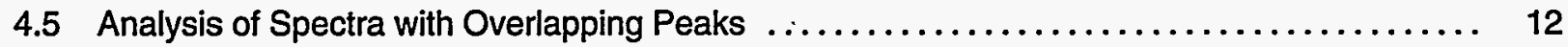

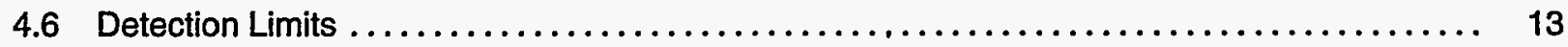

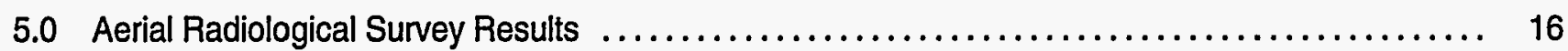

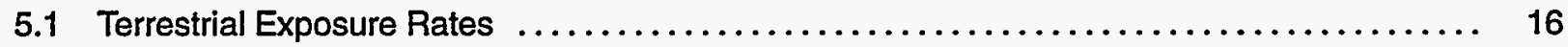

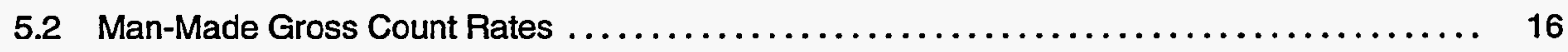

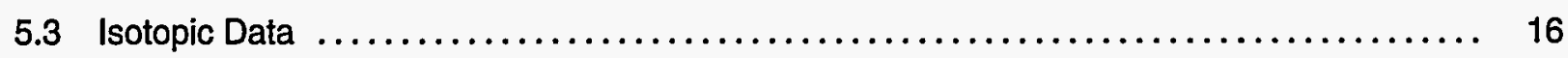

\section{Figures}

1 Pilgrim Station Nuclear Power Plant Survey Site $\ldots \ldots \ldots \ldots \ldots \ldots \ldots \ldots \ldots \ldots \ldots \ldots \ldots \ldots \ldots \ldots \ldots \ldots \ldots$

2 MBB BO-105 Helicopter with Detector Pods $\ldots \ldots \ldots \ldots \ldots \ldots \ldots \ldots \ldots \ldots \ldots \ldots \ldots \ldots \ldots \ldots \ldots \ldots \ldots \ldots \ldots$

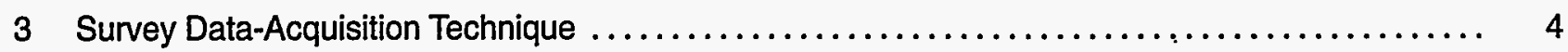

4 Typical Background Spectrum of the Survey Area $\ldots \ldots \ldots \ldots \ldots \ldots \ldots \ldots \ldots \ldots \ldots \ldots \ldots$

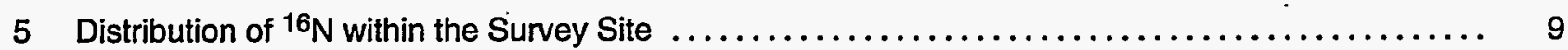


6 Terrestrial Exposure Rates within the Survey Site $\ldots \ldots \ldots \ldots \ldots \ldots \ldots \ldots \ldots \ldots \ldots \ldots \ldots \ldots$

7 Spectral Window Extraction Example $\ldots \ldots \ldots \ldots \ldots \ldots \ldots \ldots \ldots \ldots \ldots \ldots \ldots \ldots \ldots \ldots \ldots \ldots$

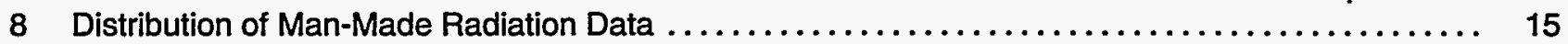

9 Man-Made Radiation within the Survey Site $\ldots \ldots \ldots \ldots \ldots \ldots \ldots \ldots \ldots \ldots \ldots \ldots \ldots \ldots \ldots$

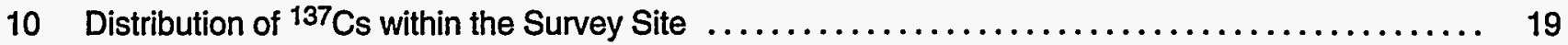

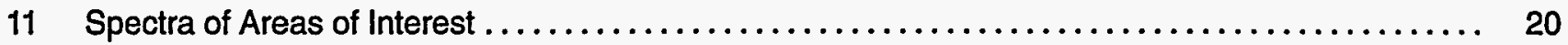

\section{Tables}

1 Approximate Detector Footprint Radius for Relative Count-Rate Contributions from Terrestrial Sources at a Survey Altitude of $150 \mathrm{ft}(46 \mathrm{~m}) \ldots \ldots \ldots \ldots \ldots \ldots \ldots \ldots \ldots \ldots \ldots \ldots \ldots \ldots \ldots$

2 Gamma-Ray Photopeak Identifications-Background within the Survey Area $\ldots \ldots \ldots \ldots \ldots \ldots$

3 Spectral Regions Used in Net Isotopic Count-Rate Calculations $\ldots \ldots \ldots \ldots \ldots \ldots \ldots \ldots \ldots \ldots .12$

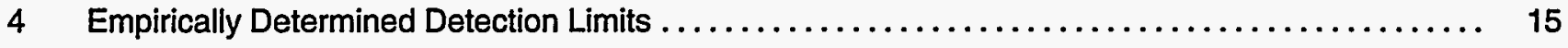

5 Comparison of Ground-Based (Pressurized lonization Chamber) and Aerial Survey Exposure Rates (Cosmic plus Terrestrial) $\ldots \ldots \ldots \ldots \ldots \ldots \ldots \ldots \ldots \ldots \ldots \ldots \ldots \ldots$

6 Gamma-Ray Photopeak Identifications-Spectrum A

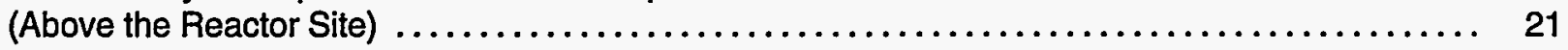

7 Gamma-Ray Photopeak Identifications-Spectrum B (East of the Reactor Site)

B-1 Calculated Critical Levels and Minimum Detectable Activity Versus

Energy for Isotopic Analysis Based on a Realistic Background Spectrum

\section{Appendices}

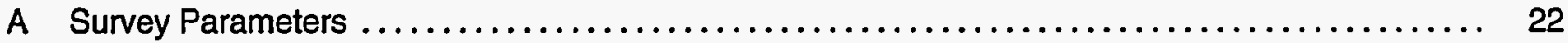

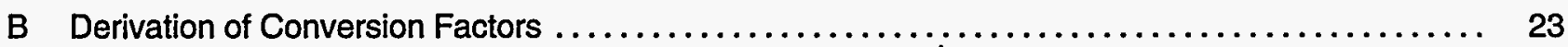

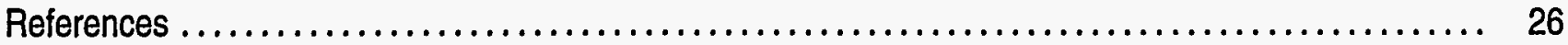




\subsection{INTRODUCTION}

An aerial radiological survey of the Pilgrim Station Nuclear Power Plant site and surrounding area was conducted by the Remote Sensing Laboratory (RSL) for the U.S. Nuclear Regulatory Commission during October 1995. This survey is part of an ongoing effort to characterize radiation levels surrounding commercial nuclear power plants. Commercial plant sites are surveyed prior to initial criticality and periodically thereafter until the plant is decommissioned and the site is returned to nonnuclear uses.

The Pilgrim Station Plant is a boiling-water reactor having a capacity of 1,998 megawatts thermal and 670 megawatts electrical operated by the Boston Edison Company. The plant began operating in 1972; a preoperational aerial radiological survey was conducted in 1971.1 The reactor was operational during the survey. No known outages or other activities, which might have influenced the radiation measurements, occurred during the four-day survey.

The survey consisted of aerial measurements of both natural and man-made gamma radiation emanating from the terrestrial surface. The purpose of this survey was to measure the exposure rates near the plant and to determine if measurable contamination from the plant had spread outside the plant site boundaries. Results are reported as radiation isopleths superimposed on aerial photographs and topographic maps of the area.

The RSL performs various types of radiological surveys for the U.S. Department of Energy (DOE) and other customers. The RSL's capabilities include an airborne radiological surveillance system called the Aerial Measuring System (AMS). Since its inception in 1958, the AMS program has carried out radiological surveys of nuclear power plants, processing plants for nuclear materials, and research laboratories. The AMS aircraft have been deployed to nuclear accident sites and in searches for lost radioactive sources. The AMS aircraft also fly mapping cameras and multispectral camera arrays for aerial photography and thermal mappers for infrared imagery. Survey operations are conducted at the request of various federal and state agencies.

\subsection{SURVEY SITE DESCRIPTION}

The Pilgrim Station Nuclear Power Plant is located along the Atlantic Ocean shoreline, south of Plymouth, Massachusetts. Nearby towns include Plymouth, Carver, Duxbury, Kingston, and South Duxbury. Bourne, Marshfield, Wareham, and numerous small communities are located near the plant site. In addjtion, there is considerable development along the shoreline near the site. Coordinates for the plant site are latitude $41^{\circ} 56^{\prime} 39^{\prime \prime} \mathrm{N}$ and longitude $70^{\circ} 34^{\prime} 40^{\prime \prime} \mathrm{W}$. Figure 1 shows the plant site. Appendix A provides a summary of the survey parameters.

\subsection{Topography and Land Use}

The topography consists of both flat and gently rolling terrain with moist soil. Most of the area has been developed for low-density housing, town sites, parks, and farms. Types of vegetation range from cranberry bogs to pasture to forested areas. The majority of the trees are deciduous. The survey was completed in early fall while most of the leaves remained on the trees. Some swampy areas and areas covered with rotting vegetation were observed, but these areas comprised only a small fraction of the survey area.

The survey site is located on the ocean, surrounded by low hills. Airborne radioactivity would be expected to move around rather than over the hills.

\subsection{Survey Area}

The Pilgrim survey area is an approximate semicircle southwest of the plant site with a three-mile radius centered on the plant site. Because the plant is located on the Atlantic shoreline, it was only necessary to extend the survey to the north and east of the plant by $1,000-1,500 \mathrm{ft}(300-460 \mathrm{~m})$ over the ocean to facilitate later data reduction. The survey area was extended north of the plant to include beach areas.

\subsection{SURVEY METHODS}

Standard aerial radiation survey techniques developed for large-area gamma radiation surveys were used. ${ }^{2}$ The survey methodology has been successfully applied to more than 300 individual surveys at various locations beginning in the late 1960 s. 


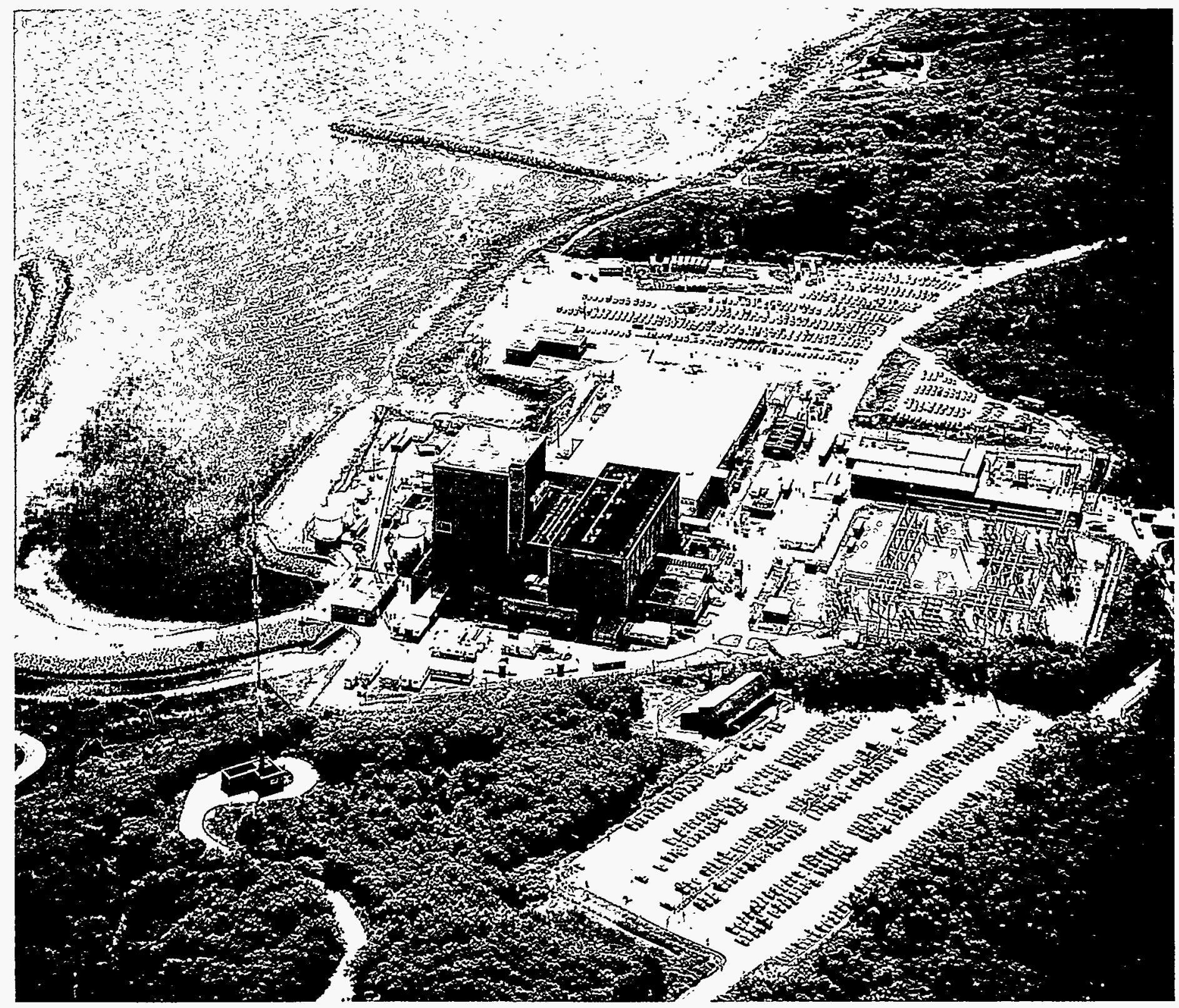

FIGURE 1. PILGRIM STATION NUCLEAR POWER PLANT SURVEY SITE

\subsection{Aerial Radiation Measurements}

A Messerschmitt-Bolkow-Blohm (MBB) BO-105 helicopter with externally mounted detector pods, shown in Figure 2, was used to collect the data. Figure 3 illustrates important details of the aerial radiological survey process. Gamma-ray spectral data were acquired at uniform spacing along a series of parallel lines that were flown in a north-south direction at an altitude of $150 \mathrm{ft}(46 \mathrm{~m})$ above ground level (AGL) and at a line spacing of $250 \mathrm{ft}(76 \mathrm{~m})$. Data were acquired continuously along these lines and recorded in one-second intervals at an airspeed of $70 \mathrm{knots}(36 \mathrm{~m} / \mathrm{s})$. This onesecond interval corresponds to a 118-ft $(36-\mathrm{m})$ data interval. During each interval, two gamma-ray spectra were detected from eight sodium iodide, thallium-activated, $\mathrm{Nal}(\mathrm{Tl})$, detectors. Other information such as air temperature, pressure, and altitude were also recorded during each interval.

The helicopter position was established by a Global Positioning System (GPS) operated in differential mode. Real-time aircraft positions were determined by an on-board GPS receiver, based on the measured position from GPS satellite data and a correction 
transmitted from a second GPS station located at a known position on the ground. The airborne GPS receiver provided continuous positional data to a microprocessor that reformatted the data for use in the RSL airborne, computerized data-logging systems. This on-board computer recorded the positional data and operated a steering indicator to aid the pilot in flying a set of equally spaced straight lines.

Real-time altitude measurements were made through a radar altimeter that measured the return time for a pulsed signal and converted this delay to aircraft altitude. For altitudes up to $2,000 \mathrm{ft}(610 \mathrm{~m})$, the manufacturer's stated accuracy is $\pm 2 \mathrm{ft}(0.6 \mathrm{~m})$ or \pm 2 percent, whichever is greater. Altitude data were also recorded by the data-acquisition system so that variations in gamma signal strength caused by altitude fluctuations could be identified.

\subsection{Data-Acquisition System}

The detection system consists of two rectangular aluminum pods. Each pod contains four $2-\times 4-\times 16$-in down-looking and one 2- $\times 4-\times 4$-in up-looking $\mathrm{Nal}(\mathrm{Tl})$ scintillation detectors. Pulse inputs from the eight 2- $\times 4-\times 16$-in detectors were summed and recorded as a spectrum, as discussed below. In addition, a spectrum from one of the $2-\times 4-\times 16$-in detectors was recorded separately to provide increased dynamic range when viewing high-radiation areas. Counts from only the $2-\times 4-\times 4$-in detector were recorded for possible use in a correction for nonterrestrial radiation contributions. The 2- $\times$ 4- $\times 16$-in detectors were surrounded by thermal insulating foam and shielded on the top and sides by $0.03-$ in $(0.076-\mathrm{cm})$ cadmium and lead sheets. The

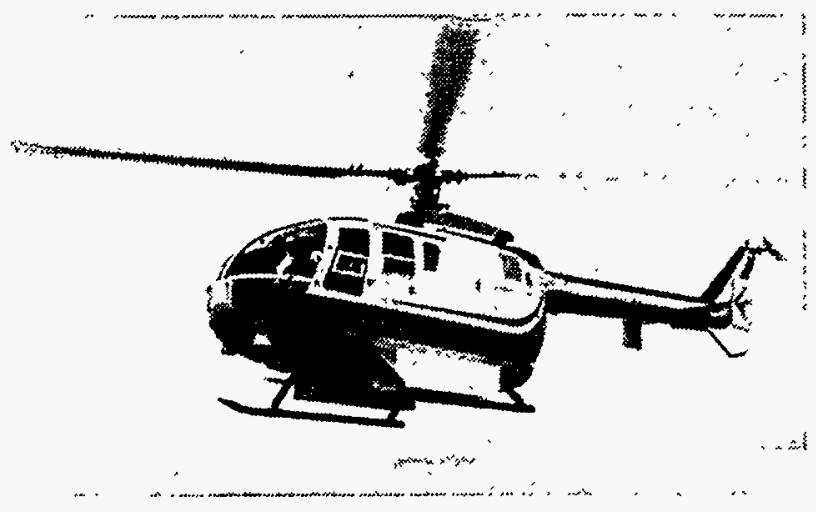

FIGURE 2. MBB BO-105 HELICOPTER WITH DETECTOR PODS
2- $\times$ 4- $\times$ 4-in detectors were shielded on the bottom and sides by the cadmium and lead sheets.

Spectral data were acquired and displayed in real time using specialized instrumentation that processes, stores, and displays spectral data. This system was developed for aerial radiological surveys and contains the necessary instrumentation in a single package. The system, called the Radiation and Environmental Data Acquisition and Recorder, Version IV, (REDAR IV), is a multi-microprocessor, portable data-acquisition, and real-time analysis system. ${ }^{3}$ It has been designed to operate in the severe environments associated with platforms such as helicopters, fixedwing aircraft, and various ground-based vehicles. The system displays the required radiation and system information to the operator, in real time, through the display of a CRT (cathode-ray tube) and through multiple readouts. Pertinent data were recorded on cartridge tapes for later analysis.

The REDAR IV system contains six subsystems: (a) two independent systems for collecting radiation data (b) a general purpose data input/output (I/O) system, (c) a tape recording/playback system, (d) a CRT display system, (e) a real-time data-analysis system, and $(f)$ a ranging system with steering calculation and display capabilities. These subsystems, which are under the operator's control, handle functions including data collection, analysis, and display; positional and steering calculations; and data recording.

Two multichannel analyzers (MCAs) in the REDAR IV system collect 1,024-channel, gamma-ray spectra (4.0 keV per channel) once every second during the survey operation. The primary MCA (for the eight-detector spectrum) has a usable dynamic range to about $100,000 \mathrm{cps}$ corresponding to an exposure rate of about $1.5 \mathrm{mR} / \mathrm{h}$ at one meter AGL. Spectral information at high-count rates begins to degrade at approximately half this rate; a single $\mathrm{Nal}(\mathrm{Tl})$ detector and second MCA are used when the system is used in high-count-rate situations.

The data-acquisition system is calibrated to a $0-4,000-k e V$ energy range using gamma-ray sources of americium-241 $\left({ }^{241} \mathrm{Am}\right)$ at $60 \mathrm{keV}$, cobalt-60 $\left({ }^{60} \mathrm{Co}\right)$ at 1,173 and $1,332 \mathrm{keV}$, and cesium-137 ( ${ }^{137} \mathrm{Cs}$ ) at $661 \mathrm{keV}$. A 28-keV low-energy threshold is selected to minimize counts from the lower part of the continuum. The summed signal derived from the eight $\mathrm{Nal}(\mathrm{Tl})$ detectors was adjusted prior to processing by the analog-to-digital converter so that the calibration peaks appeared in preselected channels in the MCA of the data-acquisition system. 


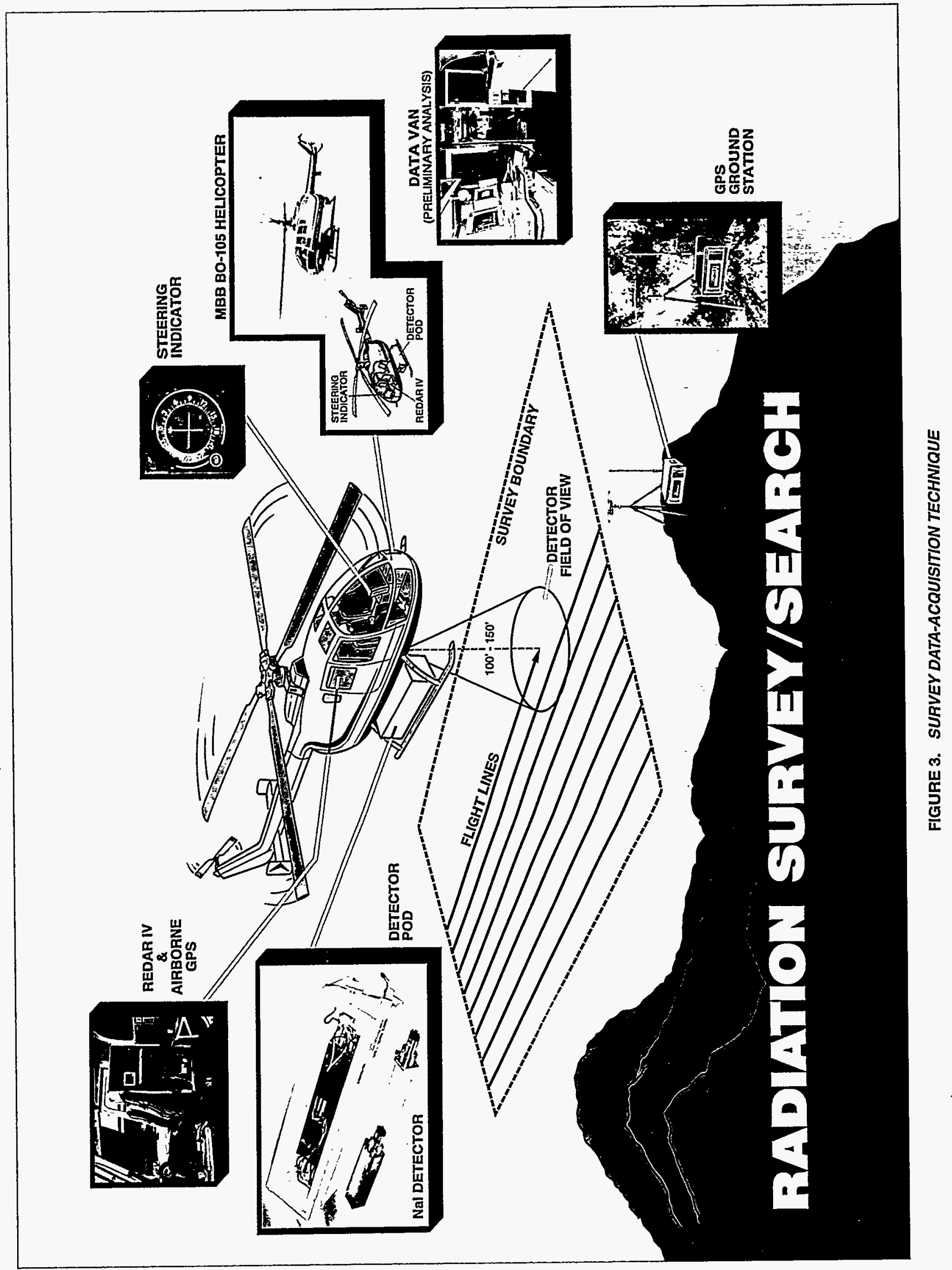


Because the energy resolution of $\mathrm{Nal}(\mathrm{Tl})$ crystals decreases with increasing energy, spectra are compressed to conserve storage space. Spectra are divided into three partitions where the detected photopeak width is approximately the same. Data in the first partition $(0-300 \mathrm{keV})$ are not compressed to permit stripping of low-energy photopeaks such as the $60-\mathrm{keV}$ photopeak from ${ }^{241} \mathrm{Am}$. The second partition $(300-1,620 \mathrm{keV})$ is compressed to $12 \mathrm{keV}$ per channel while the third partition $(1,620-4,000 \mathrm{keV})$ is compressed to $36 \mathrm{keV}$ per channel. The spectral-compression technique reduces the amount of data storage required by a factor of four.

Two full spectra, one spectrum containing data from the eight detectors and a second spectrum containing data from a single detector, and related information such as position, time, and air temperature are continuously recorded every second. The REDAR IV system has two sets of spectral memories; each memory can accumulate four individual spectra. The two memories support continuous data accumulation: one memory stores data while the other memory transfers data to magnetic tape. At a survey speed of $70 \mathrm{knots}(36 \mathrm{~m} / \mathrm{s}), 45$ data sets were acquired for each mile of flight. The Pilgrim survey contains 40,000 data sets.

\subsection{Detector Characteristics}

The detector system was designed to sense terrestrial and airborne gamma radiation having energies between 20 and $4,000 \mathrm{keV}$. This energy range includes emitted gamma radiation from naturally occurring radionuclides and almost all man-made gamma radiation sources.

$\mathrm{Nal}(\mathrm{Tl})$ detectors used in this survey are characterized by their variable sensitivity versus incident gamma energy and by a footprint size that is also energy-dependent. The variation in sensitivity with incident energy is a well-known characteristic of $\mathrm{Nal}(\mathrm{Tl})$ detectors. Detailed data on detector sensitivity can be obtained from the manufacturer. ${ }^{4}$ The dependence of the viewed footprint size with energy can be (approximately) modeled using Appendix B. Because of the large footprint, sources detected by aerial systems appear to be spread over a much larger area than would be indicated by ground-based measurements.

For uncollimated detectors, such as those used in this aerial survey, the source-to-detector distance and the attenuation by the air effectively limit the size of the viewed terrestrial area to a circular region centered beneath the detector. The size of the field of view is a function of the gamma-ray energy, the gamma-ray origin, and detector response. Radionuclide activities on or in the soil and exposure rates normalized to one meter AGL are customarily reported but only as largearea averages. Activity inferred from aerial data for a source uniformly distributed over a large area compared to the field of view of the detectors is very good and generally agrees with ground-based measurements. However, activity for a point source, a line source, or a source activity less than the detector's field of view will be underestimated, sometimes by orders of magnitude. When this occurs, the aerial data simply senve to locate and identify such sources.

Apparent source-broadening makes comparison with ground-based measurements difficult. Radionuclides that occur as hot particles are averaged by the aerial detection system, appearing as uniform large-area distributions. Ground surveys, however, would locate the hot particles within a smaller area and show the surrounding areas to be free of contamination. Table 1 contains estimates of the detection system's field of view or "footprint" size for several energies of interest.

Detector sensitivity is not constant throughout the footprint. The maximum sensitivity occurs directly beneath the detector; the sensitivity decreases with increasing horizontal distance between the source and airborne detector. In addition, the incident gamma rays from even a monoenergetic source include scattered gamma rays once the incident radiation reaches the airborne detectors. Footprint sizes are, therefore, deperident on the source location: distributed in the soil, scattered by passing through air, inside a container, etc.

\subsection{DATA ANALYSIS}

Data processing was initiated in the field using a computer analysis laboratory installed in a mobile van located near the survey site. Before leaving the site, data were examined and a preliminary analysis was completed to ensure that the raw data were satisfactory.

Standard techniques for analyzing survey data were used: terrestrial exposure rates were computed from gross count data with a correction for variations in altitude. Man-made radioactivity, ${ }^{137} \mathrm{Cs},{ }^{16} \mathrm{~N}$, and ${ }^{60} \mathrm{Co}$ activity were determined through differences between total counts in appropriate spectral windows. ${ }^{5}$ 


\section{Table 1. Approximate Detector Footprint Radius for Relative Count-Rate Contributions from Terrestrial Sources at a Survey Altitude of $150 \mathrm{ft}(46 \mathrm{~m})$}

\begin{tabular}{|c|c|c|c|}
\hline $\begin{array}{c}\text { Emitted } \\
\text { Gamma-Ray } \\
\text { Energy } \\
\text { (keV) }\end{array}$ & $\begin{array}{c}\text { Radius where } \\
\text { 99\% of Detected } \\
\text { Counts Originate } \\
\text { ft (m) }\end{array}$ & $\begin{array}{c}\text { Radius where } \\
\text { 90\% of Detected } \\
\text { Counts Originate } \\
\text { ft (m) }\end{array}$ & $\begin{array}{c}\text { Radius where } \\
\mathbf{5 0 \%} \text { of Detected } \\
\text { Counts Originate } \\
\text { ft (m) }\end{array}$ \\
\hline 60 & $650(198)$ & $353(108)$ & $155(47)$ \\
\hline 200 & 850 (259) & $435(133)$ & $178(54)$ \\
\hline 600 & $1,067(325)$ & $560(171)$ & $214(65)$ \\
\hline 1,500 & $1,715(523)$ & 772 (235) & $260(79)$ \\
\hline 2,000 & $2,145(654)$ & 850 (259) & $275(84)$ \\
\hline 3,000 & $2,862(872)$ & $1,007(307)$ & $308(94)$ \\
\hline 4,000 & $3,850(1173)$ & $1,150(351)$ & $322(98)$ \\
\hline 6,000 & $4,295(1309)$ & $1,325(404)$ & $350(107)$ \\
\hline
\end{tabular}

\subsection{Natural Background Radiation}

Natural background radiation originates from (a) radioactive elements present in the earth, (b) airborne radon, and (c) cosmic rays entering the earth's atmosphere from space. Natural terrestrial radiation levels depend on the types of soil and bedrock immediately below and surrounding the point of measurement. Within cities, the levels are also dependent on the nature of the pavement and building materials. The gamma radiation originates primarily from the uranium and thorium decay chains and from radioactive potassium. Local concentrations of these nuclides produce radiation levels at the surface of the earth typically ranging from 1-15 $\mu \mathrm{R} / \mathrm{h}$ (9-130 $\mathrm{mrem} / \mathrm{yr}$ ). Some areas with high concentrations of uranium and/or thorium in the surface minerals exhibit even higher-radiation levels, especially in the western states. ${ }^{6}$ The peaks listed in Table 2 were found in the natural background spectrum. Figure 4 shows a typical spectrum from natural background within the Pilgrim survey area.

Isotopes of the noble gas radon are members of both the uranium and thorium radioactive decay chains. Radon can diffuse through the soil and may travel through the air to other locations; therefore, the level of airborne radiation due to these radon isotopes and their daughter products at a specific location depends on a variety of factors including meteorological conditions, mineral content of the soil, and soil permeability.
Typically, airborne radon contributes from 1-10 percent of the natural background radiation.

Cosmic rays interact with elements of the earth's atmosphere and soil. These interactions produce an additional natural source of gamma radiation. Radiation levels due to cosmic rays vary with altitude and geomagnetic latitude. Typically, values range from $3.3 \mu \mathrm{R} / \mathrm{h}$ at sea level in Florida to $12 \mu \mathrm{R} / \mathrm{h}$ at an altitude of $1.9 \mathrm{mi}(3 \mathrm{~km})$ in Colorado. ${ }^{7}$

\subsection{Measured Terrestrial Exposure Rate}

The measured count rate in the aircraft differs from the true terrestrial exposure rate due to background sources in the aircraft: (a) variation of cosmic radiation with altitude, (b) temporal variation in atmospheric radon concentration, and (c) attenuation by the air of gamma rays emitted from the ground. Because the raw count-rate data over the survey area have been found to vary with time, data from each flight were normalized to data measured over a test line, which was measured at the beginning and end of each data-acquisition flight. This normalization was used to minimize the effects of variations in the natural airborne and aircraft background radiation. A test line west of the plant site, over farms and orchards, was selected for this survey.

The terrestrial exposure rate can be calculated as follows: 
Table 2. Gamma-Ray Photopeak IdentificationsBackground within the Survey Area

\begin{tabular}{l|l}
\hline Energy (keV) & \multicolumn{1}{|c}{ Identification } \\
\hline 240 & ${ }^{208} \mathrm{TI}(239 \mathrm{keV}),{ }^{212} \mathrm{~Pb}(238 \mathrm{keV})$ \\
380 & ${ }^{228} \mathrm{Ac}(339 \mathrm{keV}),{ }^{214} \mathrm{Bi}(387 \mathrm{keV}, 389 \mathrm{keV})$ \\
511 (weak) & ${ }^{208} \mathrm{TI}(511 \mathrm{keV})$, annihilation \\
610 & ${ }^{214} \mathrm{Bi}(609 \mathrm{keV})$ \\
830 (weak) & ${ }^{228} \mathrm{Ac}(795 \mathrm{keV}),{ }^{208} \mathrm{TI}(861 \mathrm{keV})$ \\
930 & ${ }^{228} \mathrm{Ac}(911 \mathrm{keV}),{ }^{214} \mathrm{Bi}(934 \mathrm{keV})$ \\
1,130 & ${ }^{214} \mathrm{Bi}(1,120 \mathrm{keV})$ \\
1,230 & ${ }^{214} \mathrm{Bi}(1,238 \mathrm{keV})$ \\
1,460 & ${ }^{40} \mathrm{~K}(1,460 \mathrm{keV})$ \\
1,750 & ${ }^{214} \mathrm{Bi}(1,765 \mathrm{keV})$ \\
2,160 & ${ }^{214} \mathrm{Bi}(2,204 \mathrm{keV})$ \\
2,560 & ${ }^{208} \mathrm{TI}(2,614 \mathrm{keV})$ \\
\hline
\end{tabular}

Exposure Rate $=($ Conversion Factor $) \cdot(G C-B)$

$$
e^{-(A \cdot a l i t u d e)}
$$

$G C$ is the gross count rate (sum of the contents of all spectrum channels) recorded by the REDAR IV system, and $A$ and $B$ are constants. $A$ is the site-specific atmospheric attenuation coefficient and has been found to be constant over the duration of a survey. $A$ is determined from data taken at multiple altitudes over the test line. $B$ represents the nonterrestrial background count rate and is calculated from test-line count rates measured before and after each survey

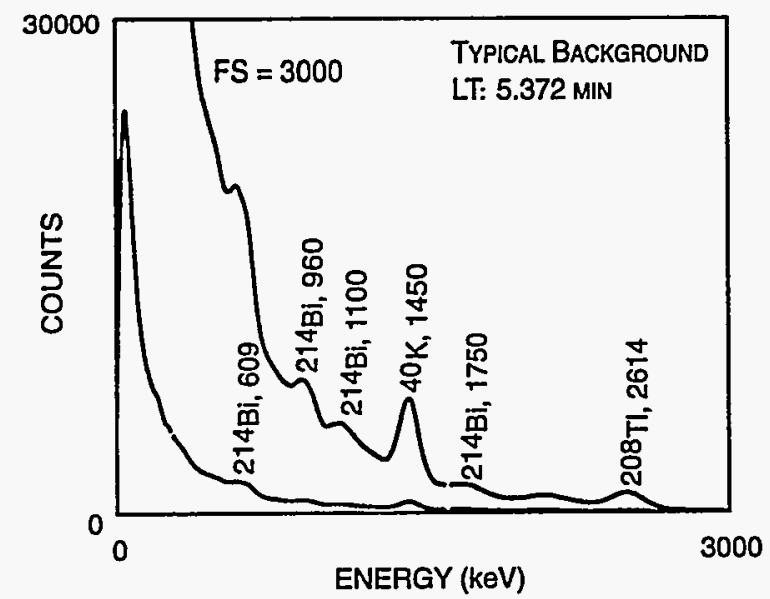

FIGURE 4. TYPICAL BACKGROUND SPECTAUM OF THE SURVEY AREA data flight (using the previously determined value of $A$ ). An average value of $B$, the recorded altitude at each data interval, and the value of $A$ are used to correct all measurements to yield the correct terrestrial gamma-emission rate. (Such a correction could be gamma-ray energy-dependent. At present, it is assumed that the relative contributions to the measured spectrum do not vary between the test line and the survey area, so an average correction is appropriate.)

A three-point sliding interval average was applied to gross count-rate data to reduce statistical fluctuations in the data:

$$
C_{i, a v g}=\left(C_{i-1}+C_{i}+C_{i+1}\right) / 3
$$

$C_{i, a v g}$ is the averaged value at the $i$ th location, and $C_{i-1}, C_{i}$, and $C_{i+1}$ are consecutive, corrected gross count rates along a single flight line. Present analysis codes do not average nearest-neighbor data on adjacent flight lines; three-point averaging has been found to be adequate. The exposure rate is calculated from this averaged gross count rate. Three-point sliding interval averaging was applied to man-made and net isotopic data prior to calculating radiation contour maps.

The conversion factor, relating count rates to exposure rates, has been determined in several ways. It can be determined empirically by comparing groundbased exposure-rate measurements with count rates 
from the airborne system. This was done for the Pilgrim survey using data obtained from comparative ground-based and aerial measurements of a wellcharacterized reference line. Two reference lines are maintained for survey calibration: one in Calvert County, Maryland, and a second in the Lake Mohave National Recreation Area near Las Vegas, Nevada. Data from the Calvert County test line were used for the Pilgrim survey because the Calvert County terrain is similar to the area covered by this survey. A conversion factor of $1.04 \times 10^{-3} \mu \mathrm{R} / \mathrm{h}$ (cps) ${ }^{-1}$ was used in the Pilgrim survey. 8,9

This conversion factor and the exposure rates calculated using it are correct only in regions of natural background radiation. Rates in regions where the gamma-ray spectrum is dominated by man-made activity were useful as relative indicators. The spectrum near the plant sites is significantly different from natural background due to the presence of gamma rays from ${ }^{16} \mathrm{~N}$. Areas where ${ }^{16} \mathrm{~N}$ was detectable are shown on Figure 5. Exposure-rate isopleths shown in Figure 6, which lie beyond the area of detectable ${ }^{16} \mathrm{~N}$, are most likely due to natural sources and are valid. Exposure-rate isopleths shown in regions of Figure 6 near the plant sites (areas of detectable ${ }^{16} \mathrm{~N}$ ) should be considered to be relative measurements.

The terrestrial exposure-rate isopleth plots are also used as a quality check on the systematic variability of survey data. In particular, exposure-rate isopleths that fall along flight lines, especially along the initial or final lines of individual flights, indicate instability in the detection system. Such variations must be corrected before the data are used. If they cannot be corrected, the uncertainty (error bars) applied to the isopleth plots must be increased to eliminate obvious systematic variations.

\subsection{Identifying Sources of Man-Made Radiation from Aerial Survey Data}

Contaminated sites are located from isopleth maps based on a man-made radiation source algorithm, referred to as the man-made gross count (MMGC). This analysis provides a general overview of contamination within the survey area and also indicates which areas should be further investigated. The MMGC algorithm is based on several observations: (a) commonly occurring man-made sources emit gamma rays having energies less than $1,394 \mathrm{keV}$ while natural background sources emit gamma rays both below and above this threshold and (b) the spectrum continuum shape is relatively constant throughout the survey area. Moreover, gamma rays detected after they are scattered (i.e., emitted by sources buried in the soil or through atmospheric scattering) will contribute to the continuum at energies below their initial energies.

The measured spectral shape is constant over the survey area assuming (a) a stable cosmic-ray emission rate; (b) a constant background due to the aircraft, airborne radon, and natural sources; and (c) a survey area where the gamma sources and soil composition change relatively slowly in comparison to the area contributing to the measured spectrum. Experience has shown that these assumptions are reasonable within statistical uncertainties over large uncontaminated survey areas. (Significant changes in the source characteristics will invalidate this assumption. For example, changes in the MMGC are seen in spectra acquired over different terrain and when airborne radon levels change.)

If there were no systematic errors in the detection system, the sum of all gamma radiation due to man-made sources would be the difference between the spectrum in question and a typical background spectrum. Unfortunately, systematic errors make this simple subtraction impractical. A more reliable comparison can be made using the ratios of the sum of all channel contents of the spectral region from $38-1,394 \mathrm{keV}$ (the region of man-made gamma emitters) to the sum of the spectral region from $1,394-3,026 \mathrm{keV}$ (the region containing mostly counts from naturally occurring gamma emitters).

$$
\begin{aligned}
& M M G C=\sum_{E=38 \mathrm{keV}}^{1394 \mathrm{keV}} C_{i}-
\end{aligned}
$$

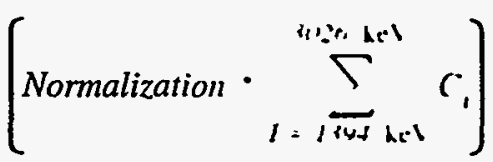

$C_{i}$ represents the contents of spectrum channels corresponding to energies within the range of summation. The MMGC is the difference for a spectrum measured over an area containing man-made radionuclides, computed using the previously determined normalization constant. The constant is computed from data measured over areas free of contamination as follows: 


\begin{tabular}{|c|c|}
\hline \multicolumn{2}{|c|}{ CONVEASION SCALE } \\
\hline $\begin{array}{l}\text { LETTER } \\
\text { LABEL }\end{array}$ & $\begin{array}{c}\text { NITROGEN - } 16 \\
\text { EXCESS COUNT RATE* }\end{array}$ \\
\hline A & $<$ \\
\hline B & $6 \cdot \quad 19$ \\
\hline C & 19. 60 \\
\hline $\mathrm{D}$ & $60 \cdot 190$ \\
\hline $\mathbf{E}$ & $190 \cdot 600$ \\
\hline $\mathbf{F}$ & $600 \cdot 1,900$ \\
\hline $\mathbf{G}$ & $1,900 \cdot 6,000$ \\
\hline $\mathbf{H}$ & $6,000 \cdot 19,000$ \\
\hline 1 & $19,000 \cdot 60,000$ \\
\hline $\begin{array}{l}\text { "Counls } \\
\text { foot (4 } \\
\text { gamma } \\
\text { up. }\end{array}$ & $\begin{array}{l}\text { end as observed at a } 150 \\
\text { er) survey altitude in the } \\
\text { y window of } 2,702 \mathrm{keV} \text { and }\end{array}$ \\
\hline
\end{tabular}

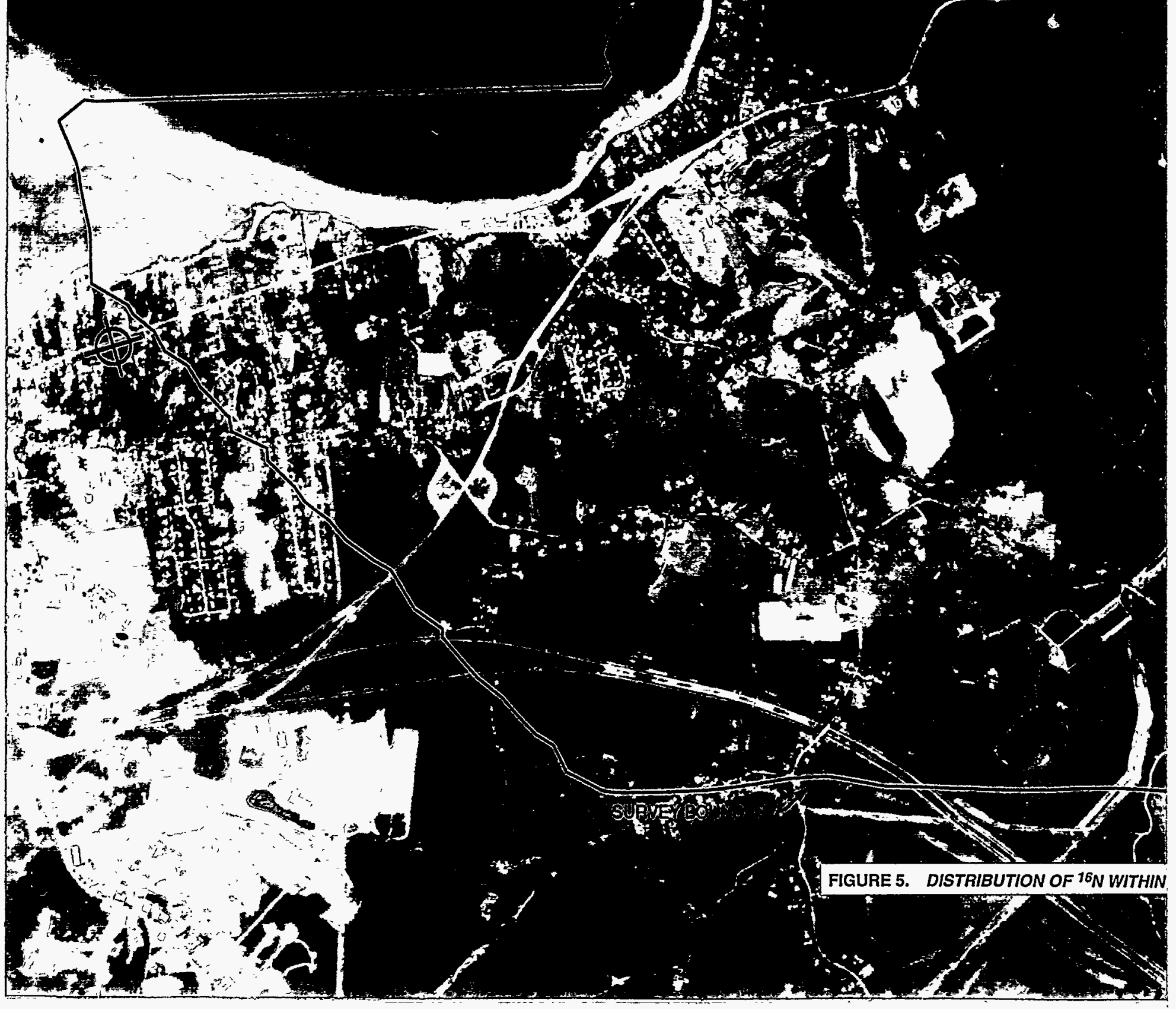




\begin{tabular}{|c|c|}
\hline \multicolumn{2}{|c|}{ CONVERSION SCALE } \\
\hline $\begin{array}{l}\text { LETTER } \\
\text { LABEL }\end{array}$ & $\begin{array}{c}\text { TERRESTRIAL GAMMA } \\
\text { EXPOSURE RATE } \\
\text { ( } \mu \mathrm{P} / \mathrm{h})^{*}\end{array}$ \\
\hline A & $<6$ \\
\hline B & $6 \cdot 8$ \\
\hline C & $8 \cdot 10$ \\
\hline D & $10 \cdot 14$ \\
\hline $\mathbf{E}$ & $14 \cdot 24$ \\
\hline $\mathbf{F}$ & $24 \cdot 42$ \\
\hline $\mathbf{G}$ & $42-84$ \\
\hline H & $84 \cdot 244$ \\
\hline \multicolumn{2}{|c|}{$\begin{array}{l}\text { "Radiation level at } 1 \text { meter above ground } \\
\text { level estimaled from aerial measurements } \\
\text { at a } 150-100 t(46-\text { meter) survey altitude } \\
\text { and includes an estimated cosmic-ray } \\
\text { contribution of } 3.6 \mu \text { R/h. }\end{array}$} \\
\hline
\end{tabular}

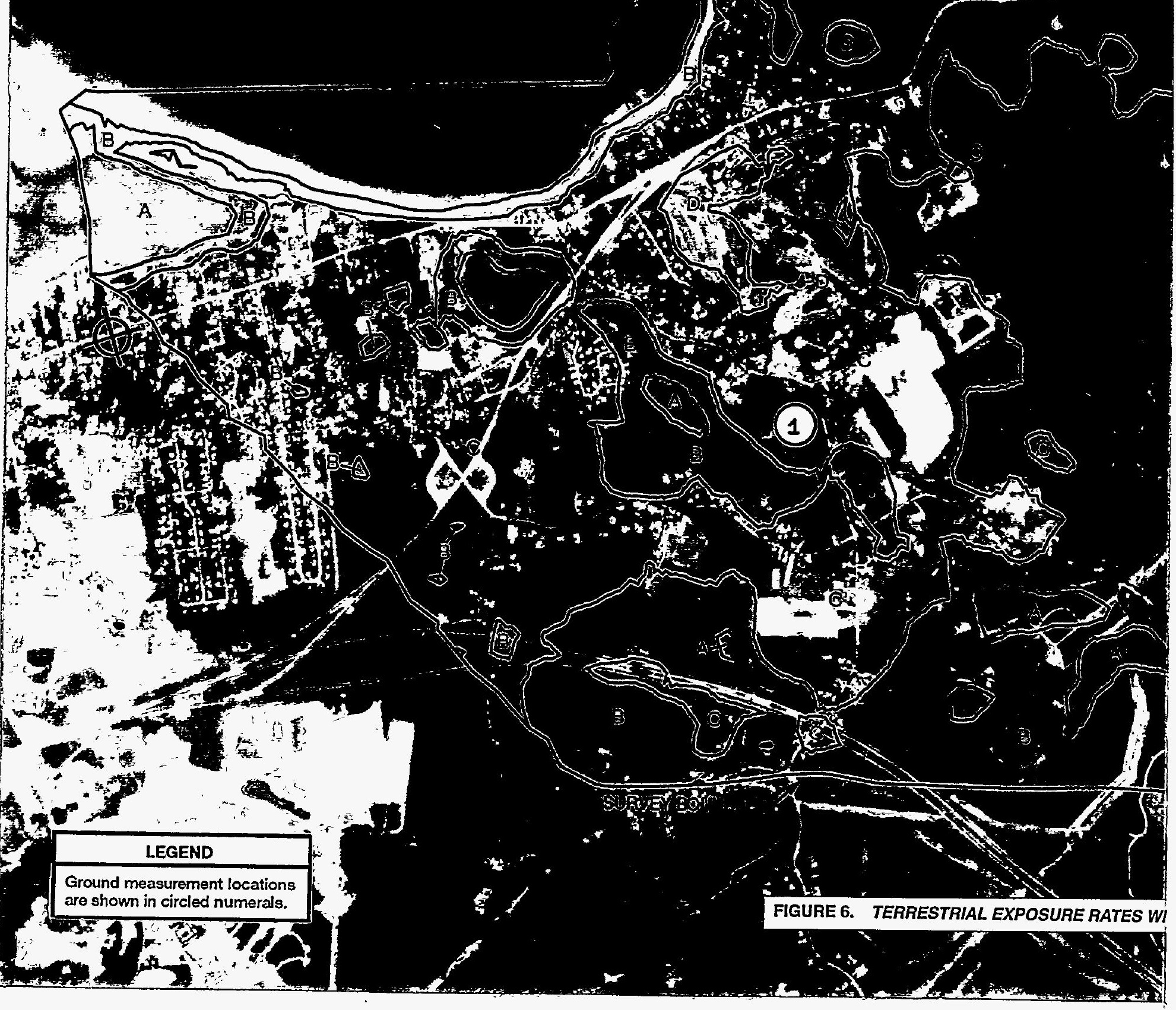




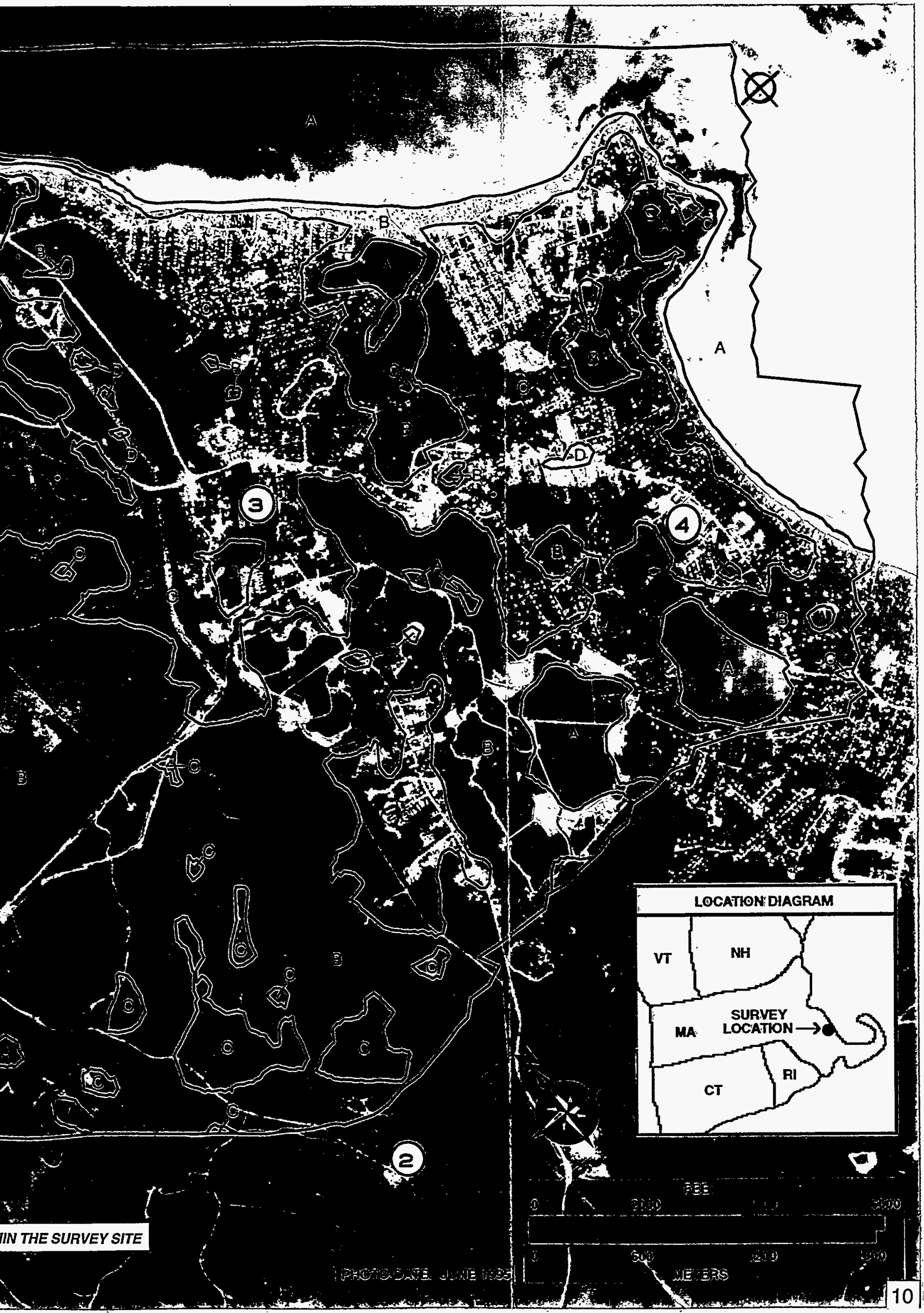




$$
\text { Normalization Constant }=\frac{\sum_{E=38 \mathrm{keV}}^{1394 \mathrm{keV}} C_{i}}{\sum_{E=1394 \mathrm{keV}}^{3026 \mathrm{keV}} C_{i}}
$$

The normalization constant is derived from the data of each flight to minimize the effects of airborne radon-222 ( $\left.{ }^{222} \mathrm{Rn}\right)$ and minor system characterization differences between flights.

\subsection{Isotope-Specific Information from Aerial Survey Data}

While the MMGC provides an indication of radioactive contamination, nuclide-specific information is important for such activities as identifying contamination sources and site remediation. Aerial survey data are also examined for spectral peaks due to various radionuclides that could be reasonably expected at the survey site: ${ }^{60} \mathrm{Co}$ and ${ }^{137} \mathrm{Cs}$. Annihilation radiation at $511 \mathrm{keV}$ was also examined as this line was prominent in previous survey data from boiling-water reactor sites. ${ }^{10}$ High-annihilation radiation (among other gamma rays) are emitted by ${ }^{16} \mathrm{~N}$ produced by an $(n, p)$ reaction on oxygen-16 $\left({ }^{16} \mathrm{O}\right)$. Nitrogen-16 is normally produced in the steam cycle of boiling-water reactors.

Spectral-stripping techniques were used to analyze aerial radiation data. (Peak fitting is not used because peak shapes from the $\mathrm{Nal}[\mathrm{Tl}]$ detectors are broad and frequently overlap.) Spectra from areas of interest (usually those with significant MMGC levels) are analyzed by subtracting, channel-by-channel, a spectrum of a known background area. These spectra are sums of all spectral data acquired within the area:

$$
\begin{gathered}
\text { Difference Spectrum }{ }_{i}=C_{i \text { site of interest }}-K_{\text {diff }} \\
\cdot C_{i, \text { background }}
\end{gathered}
$$

The $K_{\text {diff }}$ constant is selected to force the difference spectrum to zero at the high-energy side. Spectral peaks are readily visible in the difference spectrum.
The presence of an identifiable spectral peak is considered to be a requirement for proceeding with isotopic isopleth plots. Once identified, contour plots of individual radionuclides are computed using two- or three-spectral window-stripping techniques on each data spectrum acquired during the survey as follows:

$$
\begin{aligned}
\text { Isotopic Net Count }= & \sum_{E=E_{1}}^{E_{2}} C(E)-(\text { Scaling Factor }) \\
& \cdot\left[\sum_{E=E_{3}}^{E_{4}} C(E)+\sum_{E=E_{5}}^{E_{6}} C(E)\right]
\end{aligned}
$$

$C(E)$ represents the spectrum channel contents, and $E_{i}$ is the limiting energy ranges of the windows. This technique is shown graphically in Figure 7. Again, the scaling factor is adjusted to set the isotopic net count to zero for data from known background regions. Spectral window ranges used for isotopic data presented in this report are shown in Table 3.

Nitrogen-16, which is present near operating boilingwater reactors, emits an intense gamma ray at $6.13 \mathrm{MeV}$. This gamma peak is not seen in the spectrum, but the REDAR IV system records the presence of this gamma ray by storing all detected gamma counts above $4.0 \mathrm{MeV}$ in the last spectrum channel. An estimate of the extent of ${ }^{16} \mathrm{~N}$ around the plant site can be computed from the contents of the highest spectral channel and the continuum above $2,614 \mathrm{keV}$ :

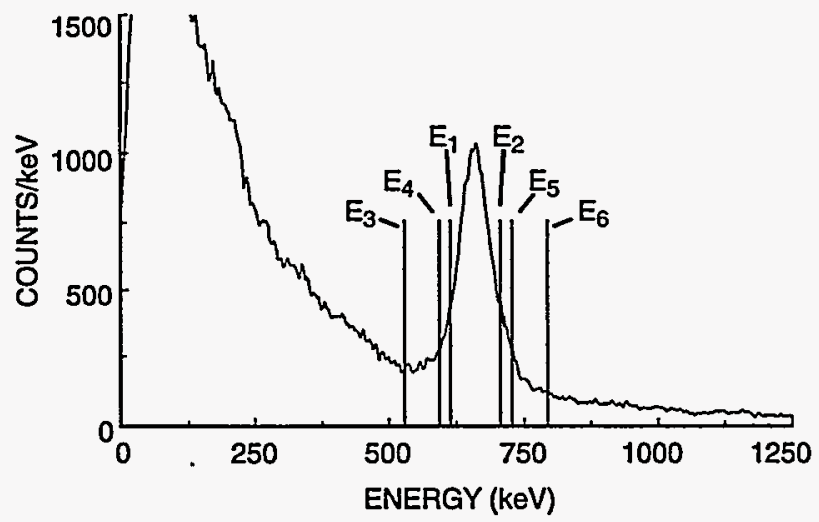

FIGURE 7. SPECTRAL WINDOW EXTRACTION EXAMPLE 
Table 3. Spectral Regions Used in Net Isotopic Count-Rate Calculations

\begin{tabular}{c|c|c|c}
\hline Isotope & $\begin{array}{c}\text { Peak Region } \\
(\mathrm{keV})\end{array}$ & $\begin{array}{c}\text { First Background } \\
\text { Region } \\
(\mathrm{keV})\end{array}$ & $\begin{array}{c}\text { Second Background } \\
\text { Region } \\
\text { (keV) }\end{array}$ \\
\hline${ }^{137} \mathrm{Cs}$ & $590-734$ & $506-590$ & $734-794$ \\
${ }^{60} \mathrm{Co}$ & $1,094-1,394$ & $1,394-3,026$ & \\
${ }^{16} \mathrm{~N}$ & $2,750-4,000$ & & \\
\hline
\end{tabular}

$$
\operatorname{Net}\left({ }^{16} N\right)=\sum_{E=2750 \mathrm{keV}}^{4000 \mathrm{keV}} C_{i}+C_{E>4000 \mathrm{keV}}-B
$$

$C_{E}>4000 \mathrm{keV}$ is the sum of all detected gamma rays above $4.0 \mathrm{MeV}$, and $B$ is a constant. A value of 8.7 was selected for $B$ by assuming that the ${ }^{16} \mathrm{~N}$ count rate far from the plant site is zero.

Nuclide-specific conversion factors take into consideration the isotopic-branching ratios, the spectral window analysis, and an assumed distribution of the source in the soil. The assumed distribution and soil attenuation at the gamma-ray energy being analyzed clearly affect the calibration. An assumed distribution of radionuclides is often a best estimate leading to an unavoidable uncertainty in the computed soil activity. Contamination may be dispersed on the surface with no contamination below the surface, or it may be distributed throughout the soil. The latter case has been found to be more probable. For Pilgrim, an exponential distribution was assumed based on actual depth profile measurements of similar radionuclides. ${ }^{11} \mathrm{Cal}-$ culation of conversion factors based on these distributions is discussed in Appendix B.

\subsection{Analysis of Spectra with Overlapping Peaks}

Survey data containing complex spectra may be subjected to multiple stripping calculations. Very complex spectra are analyzed by solving a set of linear equations relating the contribution of several gamma emitters to the overall spectrum. ${ }^{12}$

Data from directly over the Pilgrim Station site included contributions from several radionuclides, including ${ }^{16} \mathrm{~N}$. Measured spectra near the plant contain a significant continuum due to the $6.13-\mathrm{MeV}$ gamma ray; individual spectral features are broadened due to pulse pileup at high-count rates. Some spectra contain overlapping peaks due to the presence of contributions from several gamma emitters. Analysis of these data required simultaneous solution of linear equations describing the spectral contributions of each radionuclide.

Detected gamma radiation from emitting materials consists of the characteristic photopeaks, which are contained in a relatively narrow area of the spectrum, and a broad continuum at energies below the photopeak. In a spectrum which contains contributions from several emitters, the continuum from the emitter having the highest-energy photopeak will contribute to the spectrum continuum underlying the other photopeaks. The emitter with the next lower-photopeak energy will cause interference with all the photopeaks at lower energies but not with higher-energy photopeaks. The interferences occur for all emitters except the one having the lowest-energy photopeak, which causes no interference with other spectral windows.

For the gamma emitter having the highest energy, the count rate in the $n$th spectral window is

$$
W_{n}=K_{n, n} \cdot S_{n}
$$

$W_{n}$ is the sum of counts in the $n$th window, appropriate for the $n$th radionuclide; $K_{n, n}$ is a conversion factor relating activity to photopeak area; and $S_{n}$ is the activity of the $n$th radionuclide in the location where the spectral data were measured. The sum of counts in the window of the next lower-energy window, appropriate to the $(n-1)$ th emitter, is

$$
W_{n-1}=C \cdot W_{n}+K_{n-1, n-1} \cdot S_{n-1}
$$

$C$ relates the continuum contribution of the $n$th radionuclide to its corresponding detected count rate, $W_{n}$. 
It is assumed that the continuum is a function of the $n$th radionuclide energy and the size of the $n$th spectral peak. Because the count rate in the $n$th spectral region is proportional to the activity of the $n$th radionuclide, the previous equation becomes

$$
W_{n-1}=\left(K_{n-1, n-1} \cdot S_{n-1}\right)+\left(K_{n-1, n} \cdot S_{n}\right)
$$

$K_{n-1, n-1}$ is the conversion factor relating the photopeak area in the $(n-1)$ th spectral window to the activity of the gamma emitter with the next lower-energy photopeak, $S_{n-1}$, in the spectral data. $K_{n-1, n}$ is the contribution to that window from the continuum of the higher-energy gamma emitter; this contribution is proportional to the activity of the higher-energy gamma emitter, $S_{n}$, in the spectral data. The sum of counts in the first window, appropriate to the lowest-energy photopeak in the spectrum, is

$$
W_{1}=K_{1,1} \cdot S_{1}+K_{1,2} \cdot S_{2}+\ldots+K_{1, n} \cdot S_{n}
$$

This set of equations can be expressed in matrix notation. For example, a set of equations relating threewindow count rates to three gamma-emitter activities would be as follows:

$$
\left|\begin{array}{l}
W_{1} \\
W_{2} \\
W_{3}
\end{array}\right|=\left|\begin{array}{lll}
K_{1,1} & K_{1,2} & K_{1,3} \\
0 & K_{2,2} & K_{2,3} \\
0 & 0 & K_{3,3}
\end{array}\right| \cdot\left|\begin{array}{l}
S_{1} \\
\dot{S}_{2} \\
S_{3}
\end{array}\right|
$$

Subscript " 3 " refers to the highest-energy window, Subscript " 2 " is the middle-energy window, and Subscript " 1 " is the lowest-energy window.

This system of equations can, in principle, be solved for the value of $S_{i}$. In practice, determining the value of $K_{i, j}$ is required prior to solving the set of equations. These coefficients must be determined from spectra that contain contributions from only a single gamma emitter. Separating three spectral contributions requires three individual spectra, each containing only contributions from each of the three gamma emitters. Because the continuum changes with activity diștribution, shielding, etc., the single emitter spectra must be measured in an area similar to where the spectra showing multiple contributions were measured. These requirements often cannot be met, so the set of linear equations cannot be solved satisfactorily.

The ${ }^{60} \mathrm{Co}$ and ${ }^{16} \mathrm{~N}$ activities over the Pilgrim Station were successfully extracted from spectra containing multiple contributions: ${ }^{16} \mathrm{~N},{ }^{60} \mathrm{Co}$, and "terrestrial" emitters. The following is a typical set of equations:

$$
\left|\begin{array}{crr}
35.59 & 49.65 & 36.10 \\
0 & -1.30 & 22.91 \\
0 & 32.91 & -40.45
\end{array}\right| \cdot\left|\begin{array}{l}
S_{C 0-60} \\
S_{N-16} \\
S_{\text {terr. }}
\end{array}\right|=\left|\begin{array}{l}
\sum_{E=1052 \mathrm{keV}}^{E=1460 \mathrm{keV}} C_{i} \\
E=2684 \mathrm{keV} \\
\sum_{E=1472 \mathrm{keV}} C_{i} \\
E=4088 \mathrm{keV} \\
\sum_{E=2720 \mathrm{keV}} C_{i}
\end{array}\right|
$$

$C_{i}$ represents the contents of the spectral windows. Not all coefficients in the lower half of the matrix were zero. This analysis was used to compute ${ }^{60} \mathrm{Co}$ isopleths.

\subsection{Detection Limits}

Aerial radiological survey results provide information about radiation levels at the nuclear power plant site (generally well above background) and in the surrounding area (generally a relatively constant background). High levels of radiation within the plant site are expected; the plant operator usually has groundbased measurements of the site. Aerial radiological survey data provide a check on the extent of high levels of radiation near the site. Due to the large survey footprint, aerial data are only an approximate measure of the extent of site-based radioactivity. There are less costly means than aerial radiological surveys to determine that the exposure rate (ground-based radioactivity, etc.) within the site boundary of a nuclear power plant is greater than the surrounding countryside.

Radioactivity in the off-site area surrounding the plant, especially from plant site emissions, is assumed to consist of large areas (compared to the survey detection footprint) of natural and man-made radioactivity. The surrounding area is too large (and possibly inaccessible) for ground-based measurements and is best examined using aerial survey data. Man-made radioactivity from plumes of material emitted from the plant 
site is of interest. Activity outside the plant boundary will likely be much less than activity inside the plant boundaries. Detection limits used in analyzing the Pilgrim survey data were established to identify the lowest practical off-site contamination levels.

Aerial radiological survey data consist of many single measurements distributed over the survey area. It has been found from previous surveys that the survey data always contain large regions of background radiation with a few anomalous locations (i. e. , the reactor site). Knowing this, the survey data can be treated as a single, large data set for isotopic net counts and MMGC. The Pilgrim survey data contained approximately 40,000 observations, a population sufficiently large that statistical analysis can be applied. Specifically, detection limits (minimum detectable activities) can be estimated using methods similar to those developed by Currie. ${ }^{13}$ The following discussion can be applied to both MMGC rates and isotopic net count rates.

Currie defines two limits useful in analyzing survey data: (a) a critical level which is the minimum count rate where one would assume that data from a footprint are different from the background in the survey area and (b) a detection limit which is the minimum activity source that can reliably be detected. The critical level, $L_{C}$, is determined by considering the distribution of count rates in the background data set (generally the survey area outside the immediate reactor site) such that a fraction of all measured (calculated) quantities in the background data are less than or equal to $L_{C}$. This level addresses "type 1 errors" (failures to detect anomalous data). If a measurement or group of measurements is above $L_{C}$, then this region of the survey requires further examination. $L_{C}$ is defined as follows:

$$
L_{C}=k \cdot \sigma
$$

The value of $\sigma$ is determined from the distribution of survey data. The value of $k$ is selected based on the integral of a normal distribution from minus infinity to $L_{C}$, such that a desired fraction (e.g., 99.9 percent) of observations in the distribution of background data is less than $L_{C}$, assuming normally distributed data. Examination of actual distributions of survey data supports this assumption. A measured value exceeding $L_{C}$ would be assumed to indicate radiation above background within a specified confidence level.
$L_{C}$ should not be considered a dimensional quantity. Individually measured and/or computed values would be distributed around the "real" value (mean value). A single, measured observation equal to $L_{C}$ could arise from measuring a range of "actual" activity levels.

The detection limit, $L_{D}$, may be understood by considering a single measurement of one survey footprint. Multiple measurements of this footprint would yield a distribution of values with a centroid corresponding to the actual (mean) activity within the footprint. Assuming a normal distribution of measurement values, Currie defines $L_{D}$ as the minimum activity (centroid of the distribution of measurements) where a desired fraction of all single measurements will fall above $L_{C}$ :

$$
L_{D}=2 L_{C}+k^{2}
$$

Equation 15 is based on Currie's analysis for radiation-counting data (Poisson statistics). For example, greater than 99.9 percent of all measured and/or calculated values for any "detectable" source (whose activity is $L_{D}$ or greater) will be above $L_{C}$. The desired fraction (or percentage) of the cumulative distribution of observations is commonly referred to as the confidence level. This ensures that a source whose activity is equal to or greater than $L_{D}$ will "always" be detected. $L_{D}$ represents the lowest-activity level that the survey detection process will consistently find.

The lowest-radiation isopleth level in a typical contour plot would be set at (or near) $L_{C}$ while $L_{D}$ would be the stated minimum detectable activity. (Higher contours are customarily defined in terms of "levels per decade," leading to an approximate logarithmic scale.) Radionuclide activities determined from net count values that are greater than $L_{C}$ but less than $L_{D}$ are reported although they are below the "detection limit" of the instrumentation.

Figure 8 shows the distribution of calculated MMGC values from the Pilgrim survey data after applying sliding interval averaging. This distribution deviates from a true normal distribution, but a usable statistical uncertainty equal to 251 was calculated assuming a normal distribution. Isotopic net counts of ${ }^{137} \mathrm{Cs},{ }^{16} \mathrm{~N}$, and ${ }^{60} \mathrm{Co}$ were normally distributed around zero.

Empirically determined $L_{C}$ and $L_{D}$ values for the Pilgrim survey were obtained from examining the distribution of data. Table 4 shows the levels obtained from the Pilgrim survey for 99.5 and 99.9 percent confidence levels. $L_{D}$ values refer to radioactive material uniformly distributed on the surface $\left(\mu \mathrm{Ci} / \mathrm{m}^{2}\right)$, uniformly distributed throughout the soil versus depth 


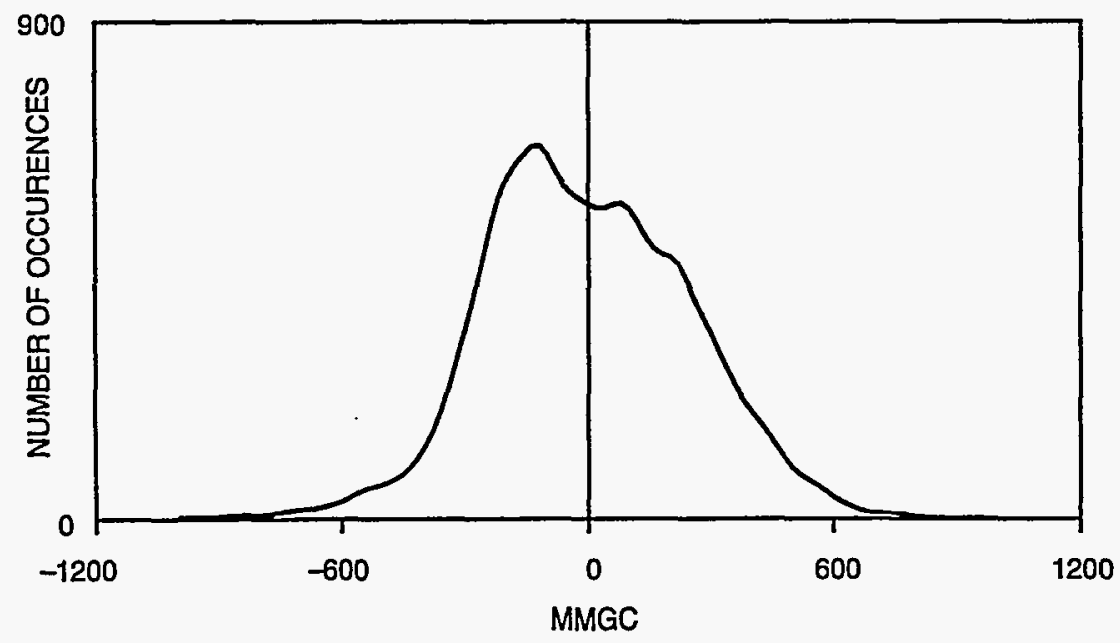

FIGURE 8. DISTRIBUTION OF MAN-MADE RADIATION DATA

(pCi/g[u]), or exponentially distributed throughout the soil versus depth (pCi/g[e]).

The previous analysis provides a rigorous means to estimate trip levels and minimum detectable activity levels for the Pilgrim survey data. Unfortunately, application of statistical techniques leads to a problem of outliers. For example, basing $L_{C}$ on a 99.5 percent confidence level will ensure that 99.5 percent of measurements from background areas (assumed to be free of man-made radiation) will fall below $L_{C}$, and 0.5 percent of all background-area data will be above $L_{C}$ leading to an erroneous conclusion that 0.5 percent of the total survey area is contaminated. For a set of 40,000 observations, 0.5 percent represents 200 survey footprint measurements.

One solution to the outlier problem is setting $L_{C}$ at a value well above the background distribution but below the highest level seen over the nuclear power plant site. This approach has been used in the past, but the resulting large increase in minimum detectable activity would fail to detect low-level contamination.

Table 4. Empirically Determined Detection Limits

\begin{tabular}{|c|c|c|c|c|c|}
\hline \multirow[b]{2}{*}{ Radionuclide } & \multirow[b]{2}{*}{$\begin{array}{c}\text { Statistical } \\
\text { Uncertainty } \\
\left.\text { ( } \sigma_{\text {survey data }}\right)\end{array}$} & \multicolumn{2}{|c|}{ Critical Level $\left(L_{C}\right)$ (rate) } & \multicolumn{2}{|c|}{ Detection Limit (LD) } \\
\hline & & $\begin{array}{c}99.5 \% \\
\text { Confidence } \\
\text { Levela }^{\text {Le }}\end{array}$ & $\begin{array}{c}99.9 \% \\
\text { Confidence } \\
\text { Level }\end{array}$ & $\begin{array}{c}99.5 \% \\
\text { Confidence } \\
\text { Level }\end{array}$ & $\begin{array}{c}99.9 \% \\
\text { Confidence } \\
\text { Level }\end{array}$ \\
\hline MMGC & 251 & 645 net cps & 779 net cps & 1297 net cps & 1568 net cps \\
\hline${ }^{60} \mathrm{Co}$ & 10.6 & 27 net cps & 33 net cps & $\begin{array}{l}0.029 \mu \mathrm{Ci} / \mathrm{m}^{2} \\
0.29 \mathrm{pCi} / \mathrm{g}(u)^{\mathrm{b}} \\
0.67 \mathrm{pCi} / \mathrm{g}(e)^{\mathrm{c}}\end{array}$ & $\begin{array}{l}0.035 \mu \mathrm{Ci} / \mathrm{m}^{2} \\
0.35 \mathrm{pCi} / \mathrm{g} \mathrm{(u)} \\
0.80 \mathrm{pCi} / \mathrm{g} \mathrm{(e)}\end{array}$ \\
\hline $16 N^{d}$ & 1.95 & 5.0 net cps & 6.0 net cps & 10.6 net cps & 21 net cps \\
\hline${ }^{137} \mathrm{Cs}$ & 12.0 & 31 net cps & 37 net cps & $\begin{array}{l}0.060 \mu \mathrm{Ci} / \mathrm{m}^{2} \\
0.77 \mathrm{pCi} / \mathrm{g} \mathrm{(u)} \\
1.49 \mathrm{pCi} / \mathrm{g}(\mathrm{e})\end{array}$ & $\begin{array}{l}0.072 \mu \mathrm{Ci} / \mathrm{m}^{2} \\
0.92 \mathrm{pCi} / \mathrm{g} \mathrm{(u}) \\
1.8 \mathrm{pCi} / \mathrm{g}(\mathrm{e})\end{array}$ \\
\hline
\end{tabular}

a Confidence level as defined in the text.

b A uniform distribution of radioactive material versus depth throughout the soil.

c An exponential distribution of radioactive material having a relaxation length of $3 \mathrm{~cm}$ was assumed. The stated value is an average over the first $2.5 \mathrm{~cm}$.

d $16 \mathrm{~N}$ is assumed to be a point source. No conversion factor is available to relate net counts per second to concentration. 
Another method deals with outliers by requiring spatial correlations between data of minimal activity. Here it is assumed that individually measured values near $L_{C}$ are outliers if the data nearest the value in question were below $L_{C}$. Data values much higher than $L_{C}$ do not require spatial correlations to be valid.

Pilgrim survey radiation isopleth plots using $L_{C}$ values, based on 95, 99, 99.5, and 99.9 percent confidence levels, were examined for spatial correlations. Confidence-level plots of 95 and 99 percent contained many outliers and were judged not to be useful. Plots containing both 99.5 and 99.9 percent confidencelevel contours were examined, and it was found that both levels yielded essentially identical features, with the 99.5 percent confidence level plot containing numerous one-footprint "contours" that were judged to be statistical outliers.

The 99.9 percent confidence level was selected as the lowest-contour level presented on the Pilgrim isopleth plots. The probability that two adjacent data measured on two different flight lines are both outliers is $(0.001)^{2}=1 \times 10^{-6}$.

It is also possible to determine $L_{C}$ and $L_{D}$ from model calculations. Such calculations are useful in planning survey operations. Appendix $B$ contains a table of predicted critical levels and detection limits for conditions similar to those of the Pilgrim survey.

\subsection{AERIAL RADIOLOGICAL SURVEY RESULTS}

Radiation isopleth plots were made of the Pilgrim site for exposure rate, MMGC, ${ }^{137} \mathrm{Cs},{ }^{16} \mathrm{~N}$, and ${ }^{60} \mathrm{Co}$. Of these, the first four are presented in this report. The ${ }^{60}$ Co plot showed activity only around the plant site, as expected, and showed no activity in the remainder of the survey area.

\subsection{Terrestrial Exposure Rates}

Figure 6 is a plot of the terrestrial exposure rates near the Pilgrim plant site. The contribution from cosmic rays and airborne radon has been removed. Minimum exposure rates are detected over water; exposure rate over land varies within a small range depending on the terrain. These correlate with differences in the terrain, which are visible on the aerial photo. The highest exposure rate was seen over the Pilgrim Station, as expected. There were no other high-exposure-rate areas in the surrounding survey area. The large bullseyes around the plant site resulted from broadening effects discussed previously. The actual high-exposure-rate area was smaller than it appears.

Three ground-based, exposure-rate measurement locations are shown on the exposure-rate plot. These were acquired using a calibrated, pressurized ionization chamber. * Ground-based and aerial survey exposure rates are compared in Table 5.

Exposure rates calculated from the aerial survey data were consistently higher than those determined from ground-based data. These differences can be attributed to the smaller footprint of the pressurized ionization chamber, variations in the spectrum at the site, a smaller than expected cosmic-ray contribution, and measurement uncertainties in the detection systems.

\subsection{Man-Made Gross Count Rates}

MMGC contours for the Pilgrim survey are shown in Figure 9. High-MMGC-rate areas were found only at the Pilgrim Station site. The plot shows the 99.9 percent confidence level and higher rates. The shape of the high-MMGC area is similar to that of the exposure rates shown in Figure 6, except that the area of highMMGC rates extends further to the west. No usefui data were available over the cross-hatched region due to the high gross count rates encountered there. Application of the MMGC algorithm over Plymouth Beach resulted in small areas of negative values. These values are the result of differences in the spectrum shape over Plymouth Beach and the survey area average; the negative values are not meaningful.

\subsection{Isotopic Data}

Evidence of man-made and naturally occurring gamma emitters was found in the Pilgrim survey area. Figure 5 shows the distribution of ${ }^{16} \mathrm{~N}$ where the lowest-level contour corresponds to a 99.9 percent confidence level. The highest levels of ${ }^{16} \mathrm{~N}$ are centered at the Pilgrim Station site, with measurable levels extending approximately $0.5 \mathrm{mi}$ from the plant. It was initially believed that these results indicated $a^{16} \mathrm{~N}$ release from the plant due to the large area over which ${ }^{16} \mathrm{~N}$ was detected.

\footnotetext{
- Reuter-Stokes, ModelRSS-112, calibrated by the manufacturer.
} 


\begin{tabular}{|c|c|}
\hline \multicolumn{2}{|r|}{ CONVERSION SCALE } \\
\hline $\begin{array}{l}\text { LETTER } \\
\text { LABEL }\end{array}$ & $\begin{array}{c}\text { MAN-MADE } \\
\text { GROSS COUNT } \\
\text { (COUNTS PER SECOND)* }\end{array}$ \\
\hline $\mathbf{A}$ & 780 \\
\hline B & 2,500 \\
\hline c & 2,500 \\
\hline D & $7,800-25,000$ \\
\hline E & $25,000 \cdot 78,000$ \\
\hline$F$ & $78,000 \cdot \quad 250,000$ \\
\hline $\mathbf{G}$ & $250,000-780,000$ \\
\hline $\mathrm{H}$ & $780,000-2,500,000$ \\
\hline \multicolumn{2}{|c|}{$\begin{array}{l}\text { "The data shown here have been } \\
\text { processed in a manner that suppresses } \\
\text { the nalural background. The resulls are } \\
\text { displayed as relathe lovels of man-made } \\
\text { radionucllide aclivity, it is nearly } \\
\text { impossible if convert the exposure rale } \\
\text { because of the complex distribution of } \\
\text { the nuclides. }\end{array}$} \\
\hline
\end{tabular}

. 


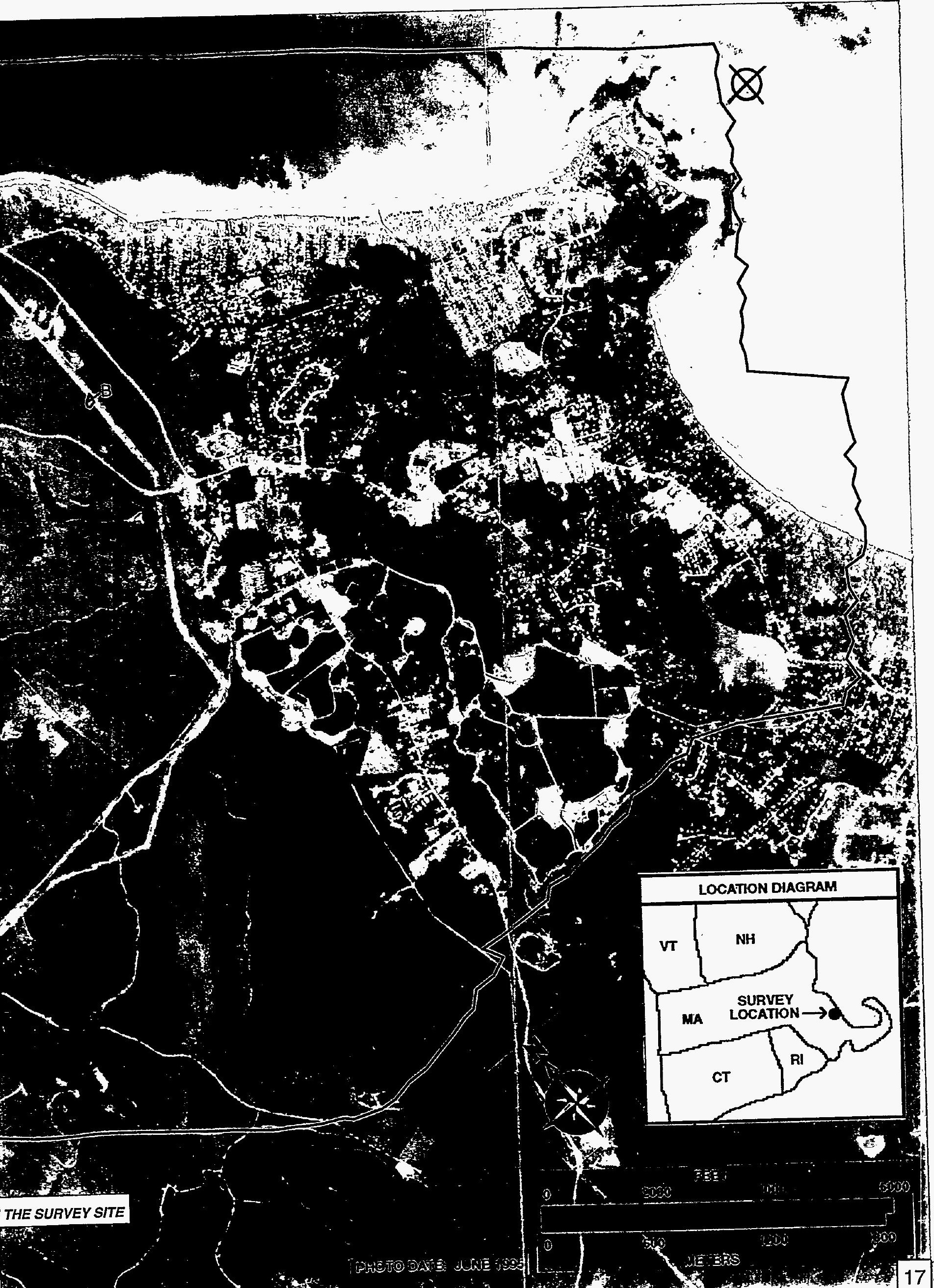




\section{Table 5. Comparison of Ground-Based (Pressurized Ionization Chamber) and Aerial Survey Exposure Rates (Cosmic a plus Terrestrial)}

\begin{tabular}{|c|c|c|}
\hline \multirow[b]{2}{*}{$\begin{array}{c}\text { Point } \\
\text { Number }\end{array}$} & \multicolumn{2}{|c|}{ Exposure Rate $(\mu \mathrm{R} / \mathrm{h}) \pm 1$ Standard Deviation } \\
\hline & $\begin{array}{l}\text { Ground-Based } \\
\text { Measurement }\end{array}$ & $\begin{array}{l}\text { Aerial Survey } \\
\text { Measurement }\end{array}$ \\
\hline 1 & $7.3 \pm 0.9$ & $9.2 \pm 0.2$ \\
\hline 2 & $6.5 \pm 0.7$ & (outside survey area) \\
\hline 3 & $8.9 \pm 0.3$ & $9.6 \pm 0.3$ \\
\hline 4 & $8.3 \pm 0.2$ & $9.4 \pm 0.2$ \\
\hline
\end{tabular}

a The cosmic contribution is assumed to be $3.6 \mu \mathrm{R} / \mathrm{h}$.

Monte Carlo photon transport calculations were used to predict expected contour maps for both point and dispersed ${ }^{16} \mathrm{~N}$ sources. ${ }^{14}$ The "point source" was a half cylinder, $30 \mathrm{ft}$ in diameter by $50 \mathrm{ft}$ long; the "dispersed" source was a large square. A realistically sized $\mathrm{Nal}(\mathrm{Tl})$ detector was also included. The results of point-source modeling show a sharply peaked relative distance from the source, increasing from a relative magnitude of unity at a 1.3-mi radius to a relative level of $10^{6}$ at a 1,000-ft radius. Modeling results for a dispersed source predict a more gradual increase over an approximate 3,000-ft distance from the edge of the plume. In addition, the results of point-source modeling show circular contours while the dispersed source contours follow the shape of the dispersed plume. The Pilgrim ${ }^{16} \mathrm{~N}$ contour data resemble the results of the point-source modeling; the center area "l" level contour represents an intensity of four orders of magnitude higher than the lowest-detectable level. The extent of this highest contour is a circle with a $600-\mathrm{ft}$ diameter. It appears that the large-area detected ${ }^{16} \mathrm{~N}$ levels resulted from an intense, contained ${ }^{16} \mathrm{~N}$ source at the plant site. There are no other areas of measurable ${ }^{16} \mathrm{~N}$ within the survey boundary.

Figure 10 shows ${ }^{137} \mathrm{Cs}$ within the survey area. The area directly over the reactor and a small area east of the reactor could not be analyzed due to the distortion of the spectrum by the very high ${ }^{16} \mathrm{~N}$ activity. Small areas of elevated ${ }^{137} \mathrm{Cs}$ were inland from the Pilgrim Station site boundary. To improve detectability, the net ${ }^{137} \mathrm{Cs}$ data were averaged over a $750-\times 750-\mathrm{ft}$ grid and replotted. These "gridded" results show a large area of slightly elevated ${ }^{137} \mathrm{Cs}$ activity extending miles from the plant site. The limits of this low-level contamination are shown by a red contour line. The large area outlined in red follows a pattern characteristic of
- worldwide fallout remaining from atmospheric nuclear testing: undeveloped areas show ${ }^{137} \mathrm{Cs}$ activity due to fallout while areas developed since the 1960s (possibly burying the fallout below the surface) show lower ${ }^{137} \mathrm{Cs}$ activity. The small areas of higher activity (outlined by black contour lines) may be concentrations of fallout or due to emissions from the Pilgrim Station.

Cesium-137 concentrations in Massachusetts due to worldwide fallout were measured as part of a 1981 study. ${ }^{15,16}$ An average level of $0.109 \pm .007 \mu \mathrm{Ci} / \mathrm{m}^{2}$ was reported; this would be $0.076 \pm .005 \mu \mathrm{Ci} / \mathrm{m}^{2}$ in 1996. The aerial survey system has a minimum detectable activity of $0.064 \mu \mathrm{Ci} / \mathrm{m}^{2}$ for ${ }^{137} \mathrm{Cs}$, assuming a 99.9 percent confidence level and three-point data averaging. The expected average ${ }^{137} \mathrm{Cs}$ level due to worldwide fallout is near the detection system's minimum detectable activity. Since fallout is usually not uniformly dispersed, "spotty" detection of ${ }^{137} \mathrm{Cs}$ would be expected. Results of the 750- $\times 750$-ft "gridded" data processing show a lower minimum detectable activity; consistent ${ }^{137} \mathrm{Cs}$ detection would be expected. These effects are confirmed by the data shown in Figure 10 . If there were ${ }^{137} \mathrm{Cs}$ ground deposition due to releases from the plant, its concentration would be below the level of worldwide fallout.

Two other gamma emitters, silver-110m (110m Ag) and ${ }^{214} \mathrm{Bi}$, could yield apparent net ${ }^{137} \mathrm{Cs}$ counts in the three-window procedure used here. (Silver-110m is an activation product resulting from neutron capture in material from reactor control rods). The ${ }^{137} \mathrm{Cs}$ plot was compared to one which mapped ${ }^{214} \mathrm{Bi}$, a naturally occurring radioactive element that emits a $609-\mathrm{keV}$ gamma ray. The presence of ${ }^{214} \mathrm{Bi}$ could cause a false 


\begin{tabular}{|c|c|}
\hline \multicolumn{2}{|c|}{ CONVERSION SCALE } \\
\hline $\begin{array}{l}\text { LETTER } \\
\text { LABEL }\end{array}$ & $\begin{array}{l}\text { CESIUM - } 137 \\
\text { EXCESS COUNT RATE* }\end{array}$ \\
\hline Red & $<10$ \\
\hline A & $10-40$ \\
\hline B & $40-130$ \\
\hline $\begin{array}{l}\text {-Counts } \\
\text { loot <4 } \\
\text { gamma } \\
\text { Ihrough } \\
\text { were pi } \\
\text { greater } \\
\text { remainl } \\
\text { red cor } \\
\text { by } 750 \text {. }\end{array}$ & 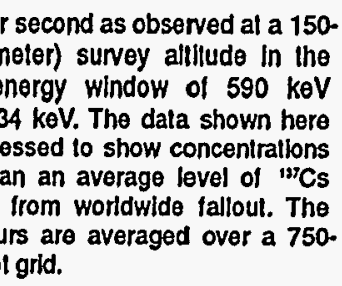 \\
\hline
\end{tabular}

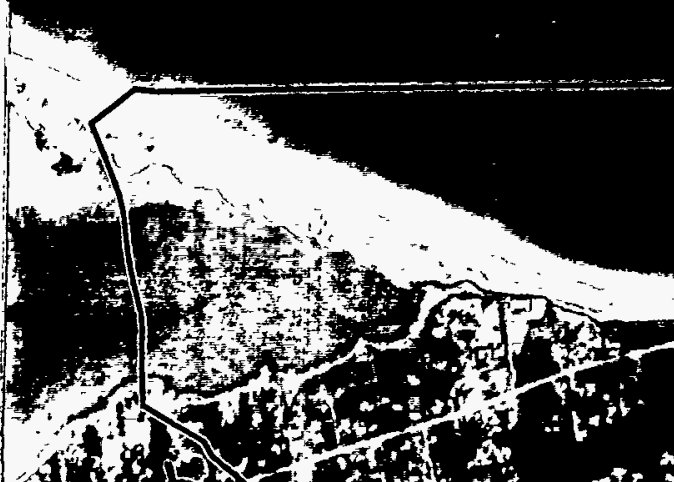

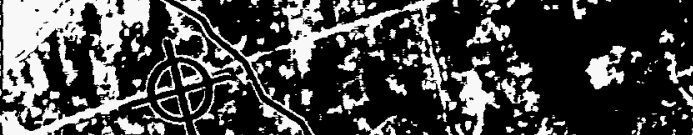

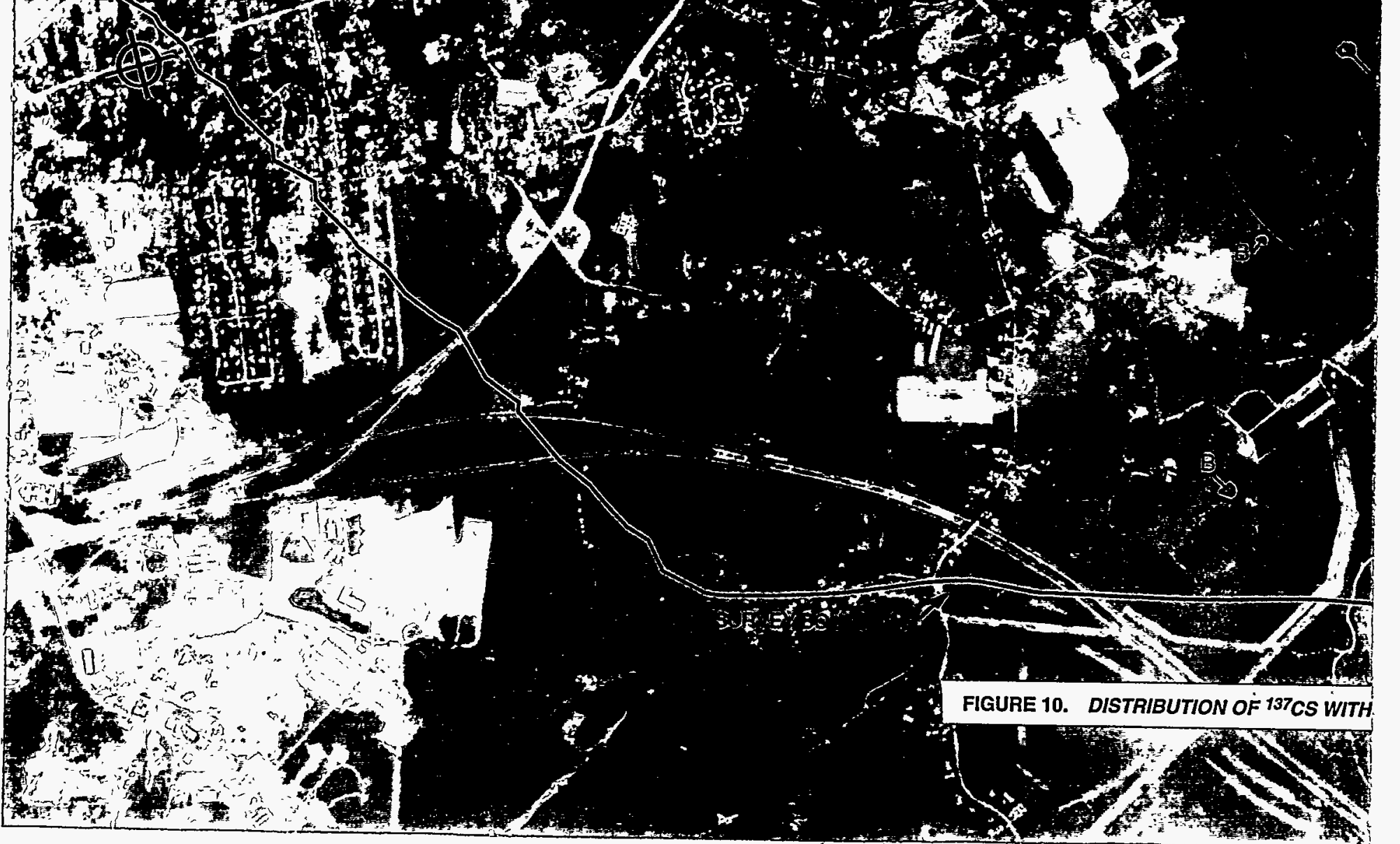




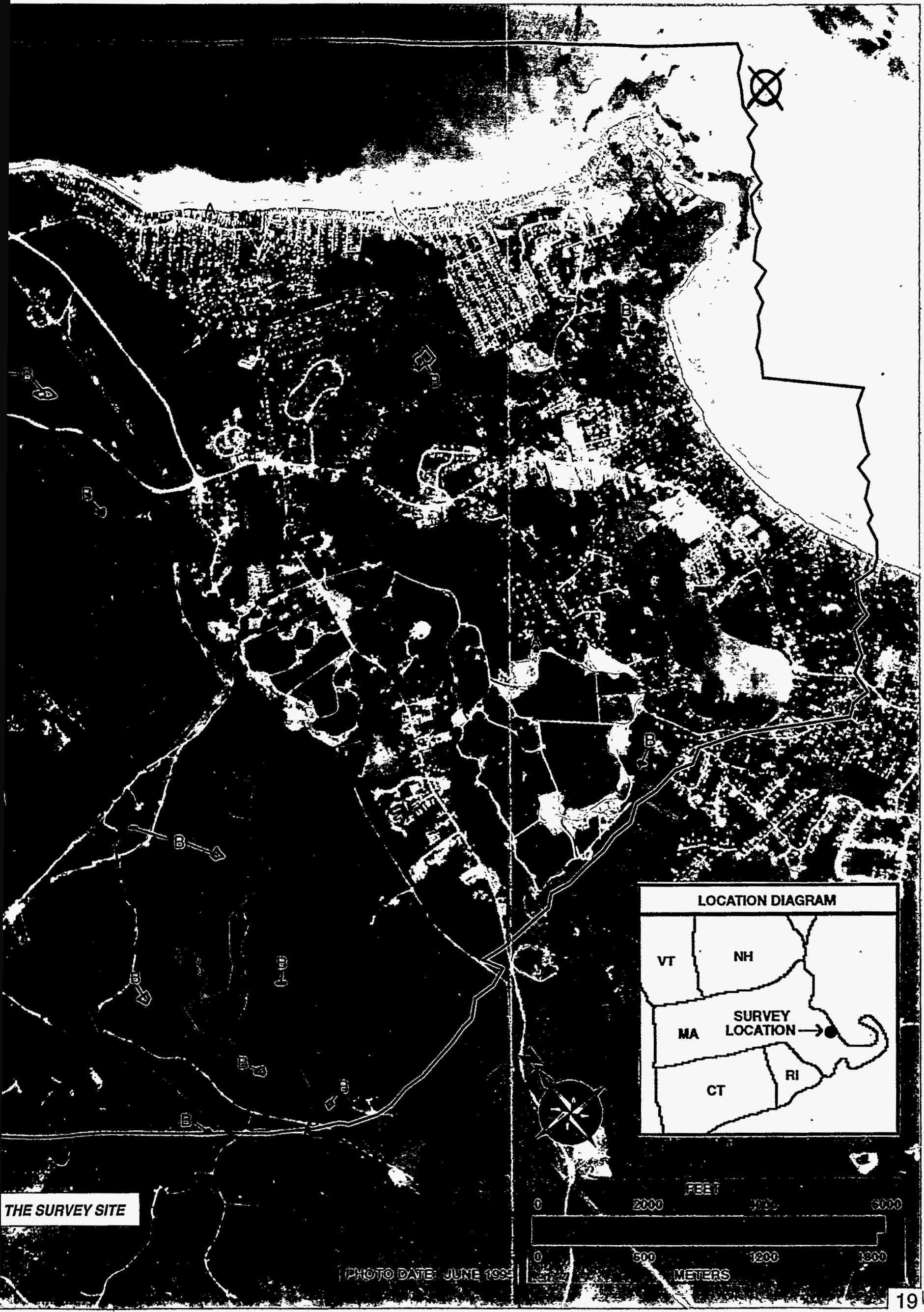


${ }^{137} \mathrm{Cs}$ net count. No correlation between ${ }^{137} \mathrm{Cs}$ and ${ }^{214} \mathrm{Bi}$ was found. Interference from $110 \mathrm{~m} \mathrm{Ag}$ is possible, but it is extremely unlikely that such interference would cause the widespread, very low-level activity that was seen.

Cobalt- 60 was detected at the Pilgrim Station site by both the direct spectral window method and by solving the linear equations set discussed in Section 4.5. Cobalt- 60 was found over the reactor building and over the area of high-exposure rate east of the reactor. No evidence of ${ }^{60} \mathrm{Co}$ contamination was found outside the Pilgrim Station site boundary.

Figure 11 contains spectra from areas of interest: Spectrum $A$ is a sum of the spectra over the reactor building while Spectrum $B$ is a sum of the spectra from above an area of high-exposure rate immediately east of the reactor.

Table 6 lists the gamma-ray photopeak energies present in Spectrum $A$ with the probable radioisotopic identifications. Spectrum A contains peaks due to ${ }^{60} \mathrm{Co}$ and naturally occurring gamma emitters: ${ }^{214} \mathrm{Bi}$, ${ }^{228} \mathrm{AC}$, and ${ }^{208} \mathrm{TI}$. Spectral features have been broadened due to the high ${ }^{16} \mathrm{~N}$ count rates.

Table 7 lists the gamma-ray photopeak energies present in Spectrum B with the probable radioisotopic identifications. Spectrum B, the high-exposure-rate area east of the reactor, contains peaks due to a multitude of probable and possible man-made emitters and naturally occurring gamma emitters. Weak gamma peaks should be considered "possible" due to the quality of spectra available from $\mathrm{Nal}(\mathrm{Tl})$ detectors.
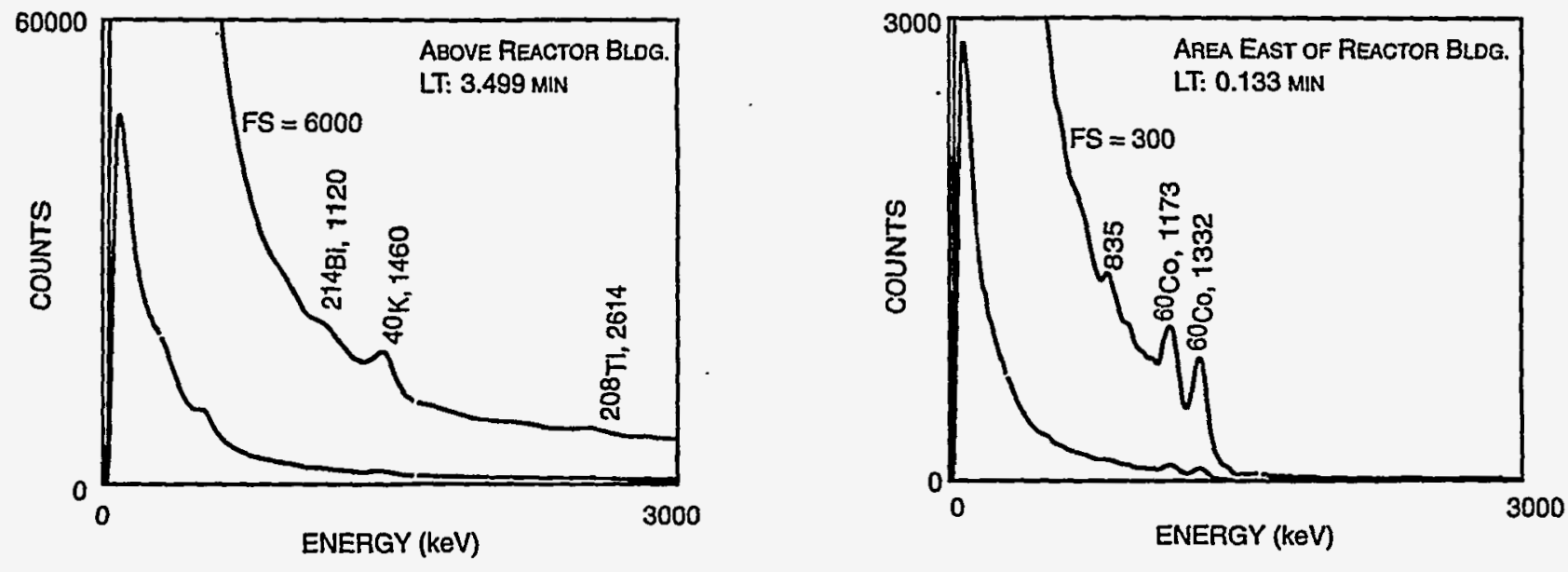

FIGURE 11. SPECTRA OF AREAS OFINTEREST 
Table 6. Gamma-Ray Photopeak Identifications-Spectrum A (Above the Reactor Site)

\begin{tabular}{|c|c|}
\hline Energy (keV) & Identification \\
\hline 520 & ${ }^{208} \mathrm{Tl}(511,583 \mathrm{keV})$, annihilation $(511 \mathrm{keV})$ \\
\hline 940 (weak) & ${ }^{214} \mathrm{Bi}(934 \mathrm{keV}),{ }^{228} \mathrm{AC}(911 \mathrm{keV})$ \\
\hline 1,130 (weak) & ${ }^{60} \mathrm{Co}(1,173 \mathrm{keV}),{ }^{214} \mathrm{Bi}(1,120 \mathrm{keV})$ \\
\hline 1,330 & ${ }^{60} \mathrm{Co}(1,332 \mathrm{keV})$ \\
\hline 1.450 & ${ }^{40} \mathrm{~K}(1,460 \mathrm{keV})$ \\
\hline 1,760 (weak) & ${ }^{214} \mathrm{Bi}(1,765 \mathrm{keV})$ \\
\hline 2,200 (weak) & $214 \mathrm{Bi}(2,204 \mathrm{keV})$ \\
\hline 2,550 & ${ }^{208} \mathrm{Tl}(2,614 \mathrm{keV})$ \\
\hline
\end{tabular}

Table 7. Gamma-Ray Photopeak Identifications-Spectrum B (East of the Reactor Site)

\begin{tabular}{|c|c|}
\hline Energy (keV) & Identification \\
\hline 511 (weak) & ${ }^{208} \mathrm{TI}(511 \mathrm{keV}),{ }^{135}$ (526 keV), annihilation \\
\hline 609 & ${ }^{214} \mathrm{Bi}(609 \mathrm{keV}),{ }^{134} \mathrm{l}(595 \mathrm{keV})$ \\
\hline 765 (weak) & ${ }^{152} \mathrm{Eu}(779 \mathrm{keV}),{ }^{228} \mathrm{Ac}(795 \mathrm{keV}),{ }^{214} \mathrm{~Pb}(786 \mathrm{keV})$ \\
\hline 835 & ${ }^{152} \mathrm{Eu}(867 \mathrm{keV}),{ }^{134} \mathrm{I}(847,884 \mathrm{keV})$ \\
\hline 940 & ${ }^{228} \mathrm{Ac}(911 \mathrm{keV}),{ }^{214} \mathrm{Bi}(934 \mathrm{keV}),{ }^{152} \mathrm{Eu}(965 \mathrm{keV})$ \\
\hline \multicolumn{2}{|l|}{1,010 (weak) } \\
\hline 1,070 & ${ }^{152} \mathrm{Eu}(1,085 \mathrm{keV}),{ }^{134} \mathrm{l}(1,072 \mathrm{keV}),{ }^{135} \mid(1,035 \mathrm{keV})$ \\
\hline 1,170 & $\begin{array}{l}{ }^{152} \mathrm{Eu}(1,112 \mathrm{keV}),{ }^{60} \mathrm{Co}(1,173 \mathrm{keV}),{ }^{214} \mathrm{Bi}(1,120 \mathrm{keV}) \text {, } \\
135 \mathrm{I}(1,132 \mathrm{keV}),{ }^{134 \mathrm{I}}(1,136 \mathrm{keV})\end{array}$ \\
\hline 1,330 & ${ }^{60} \mathrm{Co}(1,332 \mathrm{keV})$ \\
\hline 1,460 (weak, shoulder on 1,330 keV peak) & ${ }^{152} \mathrm{Eu}(1,408 \mathrm{keV}),{ }^{40} \mathrm{~K}(1,460 \mathrm{keV})$ \\
\hline 1,650 & ${ }^{214} \mathrm{Bi}(1,765 \mathrm{keV})$ \\
\hline
\end{tabular}




\section{APPENDIX A}

\section{SURVEY PARAMETERS}

Survey Site: $\quad$ Pilgrim Station Nuclear Power Plant

Survey Location: Plymouth, Massachusetts

Survey Date: $\quad$ October 19-23, 1995

Survey Coverage: $\quad 15.0 \mathrm{sq} \mathrm{mi} \mathrm{(39} \mathrm{sq} \mathrm{km)}$

Survey Altitude: $\quad 150 \mathrm{ft}(46 \mathrm{~m})$

Aircraft Speed: $\quad 70$ knots $(41 \mathrm{~m} / \mathrm{s})$

Line Spacing: $\quad 250 \mathrm{ft}(76 \mathrm{~m})$

Line Length: $\quad$ Flight lines varied in length from 1-6 mi

Line Direction: Northwest-Southeast

Number of Lines: Approximately 83

Detector Array: $\quad$ Eight $2-\times 4-\times 16$-in $\mathrm{Na}(\mathrm{Tl} l)$ detectors Two 2- $\times 4-\times 4$-in $\mathrm{Na}(\mathrm{Tl})$ detectors

Acquisition System: REDAR IV

Aircraft:

MBB BO-105 helicopter (Tail Number N40EG)

Project Scientist: A.E. Proctor 


\section{APPENDIX B}

\section{DERIVATION OF CONVERSION FACTORS}

The relationship between the photopeak net count rate observed at a distance $h$ above the surface and the activity of a monoenergetic gamma emitter distributed in the soil can be written as follows: 17,18

$$
\phi=\int_{0}^{\infty} \int_{0}^{\infty} \frac{S_{V}(z)}{4 \pi D^{2}} e^{-\left(\frac{\mu}{\rho}\right)_{a} \rho_{a} r_{a}} e^{-\left(\frac{\mu}{\rho}\right)_{s} \rho_{s} r_{s}}
$$

$2 \pi x d x d z$

where

$$
\begin{aligned}
\phi= & \text { photopeak flux at the detector } \\
S_{V}(z)= & \text { activity per unit volume; usually } \\
& \text { assumed to be a function of depth in } \\
& \text { the soil }\left[(\gamma / \mathrm{s}) / \mathrm{cm}^{3}\right] \\
D= & \text { detector-to-source distance in the air } \\
& \text { and the soil combined }(\mathrm{cm}) ; r_{a}+r_{s} \\
z= & \text { source distribution depth in the soil } \\
& (\mathrm{cm}) \\
x= & \text { integration variable; } \\
& D=\left[x^{2}+(h+z)^{2}\right]^{1 / 2} \\
(\mu / \rho)_{a},(\mu / \rho)_{s}= & \text { air and soil mass attenuation } \\
& \text { coefficients for the monoenergetic } \\
& \text { gamma energy }\left(\mathrm{cm}^{2} / \mathrm{g}\right) \\
\rho_{a}, \rho_{s}= & \text { air and soil density }\left(\mathrm{g} / \mathrm{cm}^{3}\right)
\end{aligned}
$$

For man-made radioactive material distribution patterns, the distribution of a gamma emitter in the soil can be approximated by an exponential vertical distribution of concentration:

$$
S_{V}(z)=S_{V 0} e^{-a z}
$$

$S_{V 0}$ is the activity per gram of soil at the surface, and $\alpha$ is the reciprocal of the relaxation depth. This implies that the representative volume of soil at a relaxation depth of $1 / \alpha$ contains approximately 63 percent of the source's total activity. At relaxation depths of $2 / \alpha$ and $3 / \alpha$, the representative volume of soil contains approximately 86 and 95 percent, respectively, of the total activity.
The effective area, $A$, represents the detector's capability or efficiency in detecting the specific gamma ray.

$$
N_{p}=A \phi
$$

$N_{p}$ is the photopeak net count rate, and $\phi$ is the incident flux on the detector. The effective area, in general, varies as a function of the gamma-ray angle incident to the detector face and can be written as follows:

$$
A=A_{0} R(\theta)
$$

$A_{0}$ is the detector-effective area for a unit flux perpendicular to the detector face (zero degrees) $\left(\mathrm{cm}^{2}\right), R(\theta)$ is the ratio of the detector response at an angle $\theta$ to its response at zero degrees. In practice, the effective area is measured with point radiation sources of different energies whose activities are traceable to the National Institute of Science and Technology.

Rewriting Equation B- 1 in terms of $\theta$ and $z$ and combining Equation B-4 leads to an expression which relates the measured photopeak count rate to the source activity where the conversion factor can be expressed in units of $\mathrm{cps} /\left(\gamma / \mathrm{cm}^{3}-\mathrm{s}\right)$.

$$
\frac{\left(N_{p}\right)}{S_{V 0}}=\frac{A_{0}}{2} \int_{0}^{\frac{\pi}{2}} R(\theta) \tan \theta \frac{e^{-\left(\frac{\mu}{\rho}\right)_{a} \rho_{a} h \sec \theta}}{a+\left(\frac{\mu}{\rho}\right)_{s} \rho_{s} \sec \theta} d \theta
$$

For a specific isotope, the conversion factor can be changed to units of $\mathrm{cps} /\left(\mathrm{pCi} / \mathrm{cm}^{3}\right)$ by converting gamma rays per second into $\mathrm{pCi}$. This conversion depends on the branching ratio, $\beta$, which is the number of gamma rays emitted per disintegrations. Multiplying the expression in Equation B-5 by the soil density $\left(\mathrm{g} / \mathrm{cm}^{3}\right)$, the conversion factor can be given in units of $\mathrm{cps} /(\mathrm{pCi} / \mathrm{g})$.

The average radionuclide concentration in the top $z$ $\mathrm{cm}$ in the soil can be written for an exponentially distributed gamma emitter as follows: 


$$
S_{V}^{z}=\frac{1}{z} \int_{0}^{z} S_{V 0} e^{-a z} d z=\frac{S_{V 0}}{\alpha z}\left(1-e^{-a z}\right)
$$

By substituting Equation B-6 into Equation B-5 and dividing by the soil density, the conversion factor can be expressed in units of ( $\mathrm{pCi} / \mathrm{g}) / \mathrm{cps}$ as follows:

$$
\begin{aligned}
\frac{\left(\frac{S_{V}^{z}}{\rho_{s}}\right)}{N_{p}}= & \frac{\left(1-e^{-\alpha z}\right)}{a z} \beta \\
& {\left[\frac{A_{0} \rho_{s}}{2} \int_{0}^{\frac{\pi}{2}} R(\theta) \tan \theta \frac{e^{-\left(\frac{\mu}{\rho}\right)_{a} \rho_{a} h \sec \theta}}{a+\left(\frac{\mu}{\rho}\right) \rho_{s} \sec \theta} d \theta\right]^{-1} }
\end{aligned}
$$

Examples of computed minimum detectable activities and conversion factors for soil concentration from point radiation sources can be found in the literature. ${ }^{19,20}$

Estimated conversion factors can be computed for specific survey conditions through numerical integration of the previous equation. Combining these conversion factors and representative spectral background count rates and calculating Currie's detection limits yield dimensioned values of the detection limits. The limits shown in Table B-1 have been calculated for the Pilgrim survey using the Calvert County, Maryland, reference line as the spectral background. 


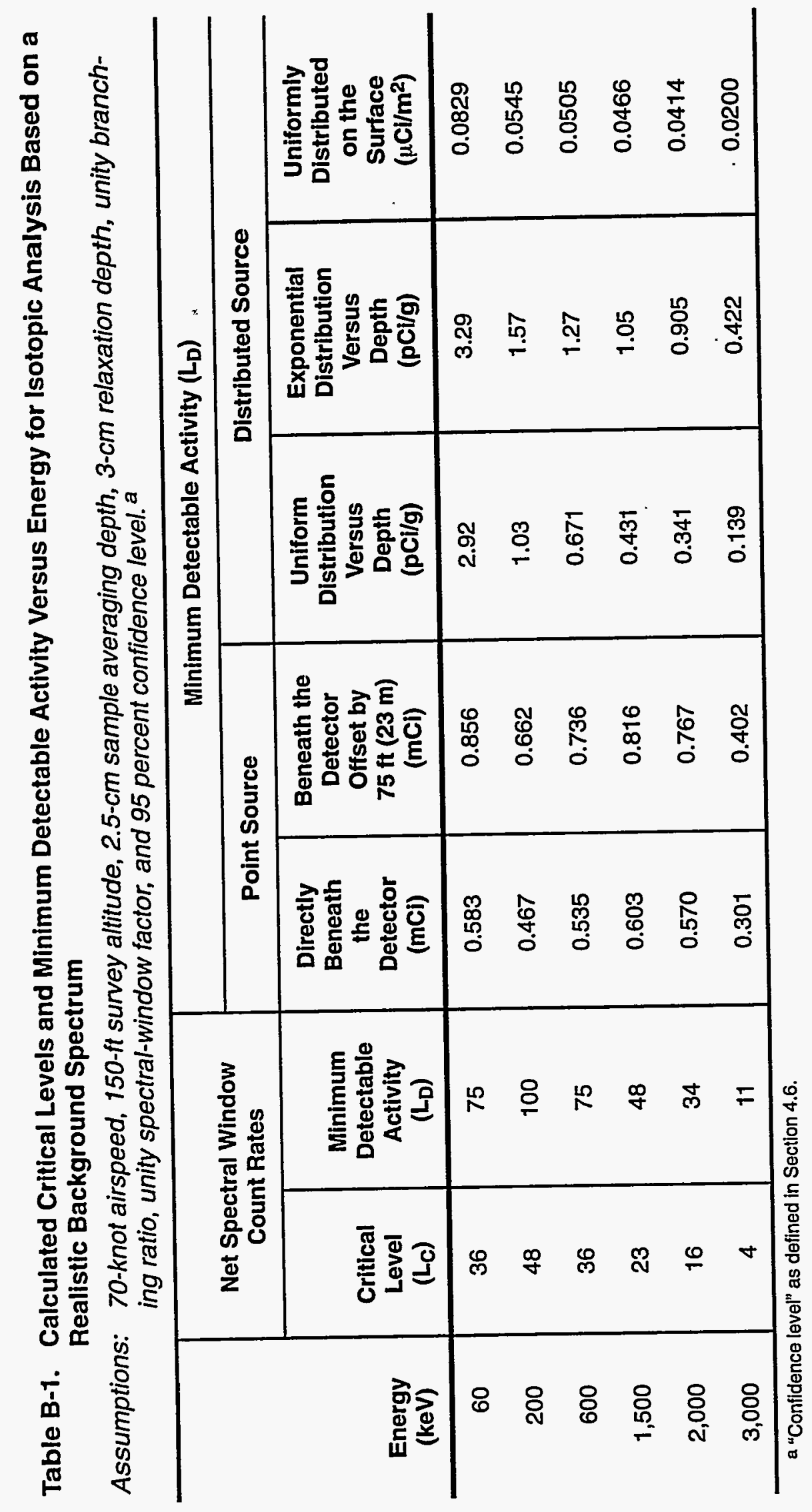




\section{REFERENCES}

1. Radiological Survey of the Area Surrounding the Pilgrim Station, Plymouth, Massachusetts. Report No. EGG-1183-1607, 1973; EG\&G, Las Vegas, NV.

2. Jobst, J.E. "Recent Advances in Airborne Radiometric Technology," Remote Sensing Technology, Proceedings of a Symposium on Remote Sensing Technology in Support of the United States Department of Energy, 23-25 February 1983. Report No. EGG-10282-1057, 1985; EG\&G/EM, Las Vegas, NV.

3. Radiation, Environmental Data Acquisition and Recorder System (REDAR IV) Manual. 1981; Aerial Measurementts Operations, EG\&G, Las Vegas, NV.

4. Belian, J.; R. Dayton. NaI(Tl) Scintillation Detectors. Bicron Corporation.

5. Hendricks, T.J. "Radiation and Environmental Data Analysis Computer (REDAC) Hardware, Software, and Analysis Procedures," Remote Sensing Technology, Proceedings of a Symposium on Remote Sensing Technology in Support of the United States Department of Energy. Report No. EGG-10282-1057, 1985; EG\&G/EM, Las Vegas, NV.

6. Lindeken, C.L.; K.R. Peterson; D.E. Jones; R.E. McMillen. "Geographical Variations in Environmental Radiation Background in the United States," Proceedings of the Second International Symposium on Remote Sensing Technology the Natural Radiation Environment, August 7-11, 1972, Houston, Texas. National Technical Information Service; 1972; pp 317-332. Springfield, VA.

7. Klement, Jr., A.W.; C.R. Miller; R.P. Minx; B. Shleien. Estimates of Ionizing Radiation Doses in the United States, 1960-2000. U.S. EPA Report ORP/CSD72-1, 1972; EPA, Washington, D.C.

8. Proctor, A.E. [Oral communication with M.F. Mohar, Washington Aerial Measurements Organization, Andrews Air Force Base]. 1995 October.

9. Mohr, R.A. Ground Truth Measurements at the Calvert County, Maryland Test Line. Report No. EGG-10282-2066, 1985; EG\&G/EM, Santa Barbara, CA.

10. Maurer, R. An Aerial Radiological Survey of the Quad Cities Nuclear Power Station and Surrounding Area. Report No. EGG-10617-1219, 1992; EG\&G/EM, Las Vegas, NV.

11. Essington, E.H.; E.B. Fowler. "Distribution of Transuranic Radionuclides in Soils, A Review", Transuranic:s in Natural Environments, A Symposium at Gatlinburg, October 1976. NVO-178, 1977; pp 41-77.

12. Feimster, E.L. An Aerial Radiological Survey of L Lake and Steel Creek, Savannah River Sitc'. Report No. EGG-10617-1146, 1992; EG\&G/EM, Las Vegas, NV.

13. Currie, L.A. "Limits for Qualitative Detection and Quantitative Determination; Applicatıon to Radiochemistry," Analytical Chemistry 40, No. 3, March 1968; pp 586-593.

14. Proctor, A.E. [Oral communication with Laura Tunnel, Special Technologies Laboratory]. 1997 January.

15. Carey, P.W.; H. W. Beck. Distribution Throughout Utah of ${ }^{137} \mathrm{Cs}$ and ${ }^{239+240}$ Pu from Ne'vudu Te'st Sitl" Detonations. Report No. EML-400, 1981; DOE/EML, New York.

16. Proctor, A.E. [Oral communication with Stuart C. Black, Bechtel Nevada]. 1997 January.

17. Tipton, W.J.; A.E. Fritzsche; R.J. Jaffe; A.E. Villaire. An In Situ Determination of ${ }^{241}$ Am on the Enewetak Atoll. Report No. EGG-1183-1778, 1981; EG\&G, Las Vegas, NV.

18. Environmental Radiation Measurements, Recommendations of the National Council on Radiation Protection and Measurements. Report No. 50, 1976; pp 32-34. National Council on Radiation Protection, Washington, D.C. 
19. Beck, H.L.; J. DeCampo; C. Gogolak. In Situ Ge(Li) and NaI(Tl) Gamma Ray Spectrometry. Report No. HASL-258, TID-4500, 1972; U.S. AEC Health and Safety Laboratory, New York, NY.

20. Reiman, R.T. In Situ Surveys of the U.S. Department of Energy's Rocky Flats Plant, Golden, Colorado. Report No. EGG-10617-1129, 1991; EG\&G/EM, Las Vegas, NV. 